\title{
A review of Beliche Dam
}

\author{
E. E. AlONSO*, S. OLIVELLA* and N. M. PINYOL*
}

Beliche Dam, a zoned earthdam with rockfill shoulders and a central clay core, experienced large collapse settlements due to reservoir impounding and direct action of rainfall. Long-term field records of vertical and horizontal displacements are available as well as a set of largescale laboratory tests on rockfill specimens. It has been the subject of several numerical analyses that failed to capture the relevant effect of weather conditions on the behaviour of the dam. Recent developments in the constitutive modelling of rockfill allow a substantial improvement of modelling capabilities, and this is illustrated in the paper. Laboratory test results under dry and flooded conditions were interpreted, and material parameters were identified. The complete history of dam construction, impoundment and rainfall was then simulated by means of a coupled flow-deformation model. Deformations during construction and impoundment have been reproduced. Long-term deformations have consistently been related to rainfall records. In general, long-term deformations are controlled by the varying wetting history of the dam shoulders and by an intrinsic deformation component. The wetting action comes to an end when the relative humidity of the rockfill reaches $100 \%$ for the first time. The paper also discusses scale effects and the role of rockfill permeability in the development of deformations.

KEYWORDS: case history; collapsed settlement; constitutive relations; dams; laboratory tests; numerical modelling and analysis
Le barrage de Beliche, digue de terre zonée avec épaulements en enrochement en vrac et noyau central en argile, a connu de grands affaissements en raison de l'endiguement du réservoir et de l'action directe des eaux de pluie. Il existe des données de terrain à long terme sur les déplacements verticaux et horizontaux ainsi qu'un lot d'essais grandeur nature en laboratoire réalisés sur des spécimens d'enrochement en vrac. Ceci a été le sujet de plusieurs analyses numériques qui n'ont pas réussi à expliquer pertinemment l'effet des conditions climatiques sur le comportement du barrage. Les progrès récents en modélisation constitutive des enrochements permettent d'améliorer de manière substantielle les capacités de la modélisation; c'est ce que nous illustrons dans cet exposé. Nous avons interprété les résultats des essais en laboratoire en conditions sèches et noyées et nous avons identifié les paramètres matériels. Nous avons alors simulé l'historique complet de la construction du barrage, de l'endiguement et de l'eau de pluie au moyen d'un modèle couplé flux-déformation. Nous avons reproduit les déformations pendant la construction et l'endiguement. Les déformations à long terme ont été liées de manière constante aux précipitations. En général, les déformations à long terme sont contrôlées par l'historique de mouillage variant des épaulements du barrage et par une composante de déformation intrinsèque. L'action mouillante arrive à sa fin lorsque l'humidité relative de l'enrochement atteint $100 \%$ pour la première fois. Dans cet exposé, nous étudions également les effets d'échelle et le rôle de la perméabilité de l'enrochement sur le développement de déformations.

\section{INTRODUCTION}

Beliche Dam has attracted wide interest from geotechnical researchers working in the field of earth and rockfill dam behaviour. The reason for the continued interest in Beliche probably lies in the availability of a set of large-scale laboratory tests (oedometer and triaxial) on the rockfill materials, as well as a comprehensive set of field monitoring data, which covers the construction and impoundment, and several years of dam operation. Published papers and doctoral dissertations that have addressed the analysis of the dam constitute a valuable source of information concerning both the laboratory and field behaviour of rockfill materials and the evolution of numerical techniques for dam analysis. Of particular relevance are the papers published by Naylor et al. (1986, 1997). These papers are the immediate reference for the work presented here. Before an evaluation of the achievements and limitations of the previous work is presented, the main features of the dam and its behaviour will be briefly presented. Comprehensive information is provided

Manuscript received 19 July 2004; revised manuscript accepted 7 February 2005.

Discussion on this paper closes on 1 November 2005, for further details see p. ii.

* Department of Geotechnical Engineering and Geosciences, Universitat Politècnica de Catalunya, Barcelona, Spain. in the two references mentioned and in the additional publications mentioned later.

Beliche Dam is a $54 \mathrm{~m}$ high earth and rockfill dam located in the Algarve, Portugal. It has a moderately curved shape in plan view. A central cross-section showing the position of stress cells, open pipe piezometers, extensometers and surface settlement markers is reproduced in Figs 1 and 2. The design is classic: a central core of low-plasticity clay is stabilised by two rockfill shells. Two zones are distinguished on each shell: an inner one, made of lightly compacted fractured schists, and a harder outer one, made of compacted greywacke. Schists and greywackes are relatively soft rocks, and large deformations (short and long-

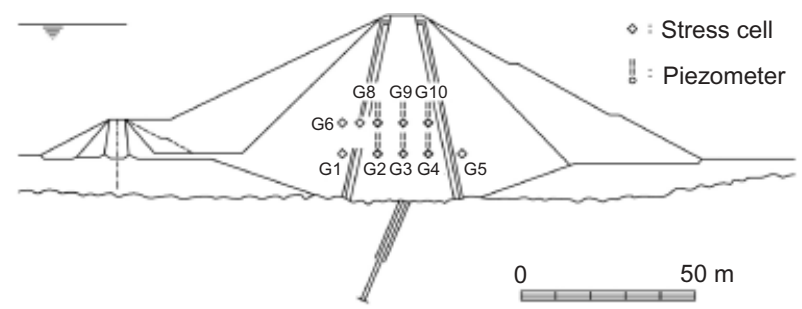

Fig. 1. Central cross-section (P7) of Beliche Dam: position of stress cells and piezometers (Naylor et al., 1997) 


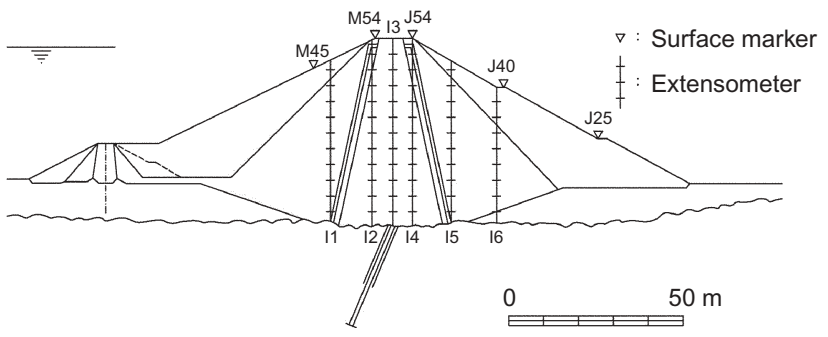

Fig. 2. Central cross-section (P7) of Beliche Dam: position of extensometers and surface settlement markers (Naylor et al., 1997)

term) may be expected. Naylor et al. $(1986,1997)$ state that the inner rockfill was made deformable on purpose, in order to avoid arch effects on the core, and therefore to ensure a significant compression state of the core, with the purpose of avoiding cracking phenomena in the core. Construction started in 1984. When the dam height reached $47 \mathrm{~m}$ (January/February 1986) the reservoir level reached an unexpected temporary elevation of $29 \mathrm{~m}$ over foundation level due to heavy rains. Significant collapse of the upstream shell was recorded. This is shown in Fig. 20, which shows the vertical displacements observed in extensometer I1, located within the upstream inner shell (line B corresponds to December 1985, and line $\mathrm{C}$ to February 1986). Maximum accumulated vertical displacements, in excess of $0.80 \mathrm{~m}$, were recorded at mid-height. Note also (Fig. 20, extensometer I6) that the downstream shell, not affected by the impoundment, reached similar settlements.

Once the dam was completed in March 1986, it was subjected to the rainfall and reservoir level evolution reproduced in Fig. 3(a). Settlements and horizontal displacements of the surface markers were recorded against time. Fig. 3(b) shows the recorded evolution of vertical displacements at marker M54 in the three centre sections of the dam $(6,7$ and 8) (see Fig. 1 of Naylor et al., 1997) and the calculated values reported by Naylor et al. (1997). The figure shows a distinct correlation between measured settlement rates and
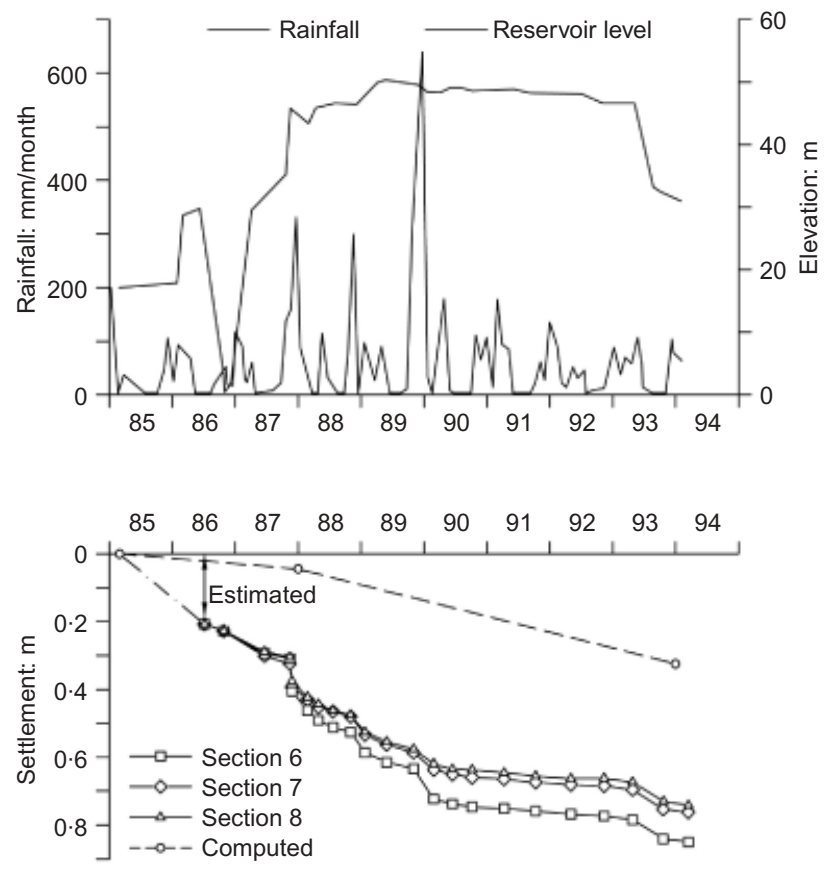

Fig. 3. (a) Rainfall intensity and reservoir level after dam construction; (b) vertical settlements at marker M54 (continuous line) and predictions by Naylor et al. (1997) (broken line) (after Naylor et al., 1997) extreme periods of rainfall intensity during the first five years of operation of the dam. Further data concerning the behaviour of the dam will be presented later in connection with the analysis reported in this paper.

\section{Review of previous work}

The paper by Naylor et al. (1986) is a prediction exercise of the construction of Beliche Dam. It was performed before actual field data became available. Two non-linear elastic models were used (a hyperbolic model and a K-G model (where $\mathrm{K}$ is bulk coefficient and $\mathrm{G}$ is shear modulus)). Model parameters were derived from back-analysis of triaxial and oedometer tests on compacted 'dry' samples. Specimens tested under triaxial conditions were flooded once they had reached the maximum deviatoric load. A sudden reduction in deviatoric load was measured. The vertical strain rate was maintained, and a reduced limiting strength was finally recorded, this time for saturated conditions. No attempt was made in Naylor's paper to model this flooding stage of the tests. Five material parameters were required for the K-G model and eight for the hyperbolic model. The analysis was performed in terms of total stresses and material parameters corresponding to the dry stage of the tests performed. Small quantitative differences were found between the two models. A maximum settlement of $40 \mathrm{~cm}$ was predicted at the end of construction, for the centre of the dam. This was a clear underestimation of actual values, which were later attributed to the collapse effects associated with the unexpected partial impoundment of January-February 1986.

Collapse effects in rockfill dam behaviour were first introduced into finite element analysis by Nobari \& Duncan (1972). The idea is to measure collapse strains by performing dry and wet oedometer and triaxial tests on rockfill samples. The calculation starts by performing the finite element (FE) analysis using the set of material parameters corresponding to dry conditions; then collapse is numerically simulated in two stages. First, the stress change due to saturation (at constant strain) is determined on the basis of the experimental data. In the second stage nodal forces that restore equilibrium are applied. The computed strains reproduce the collapse strains. The procedure has been followed by some authors: Veiga Pinto (1983); Justo \& Saura (1983), who performed a 3D linear elastic analysis of El Infiernillo Dam; and Soriano et al. (1990). Naylor et al. (1989) generalised the method for arbitrary constitutive models. It required the knowledge of two sets of constitutive parameters for dry and saturated conditions. The method is only approximate even if only the effects of full saturation (which is the case of the upstream shell) are required, because it does not guarantee that the actual stress path experienced in the field is followed by the calculation procedure. The point to underline here, recognised also by Naylor et al. (1997), is that the procedure is essentially a computational device, not necessarily associated with a physical reality.

Naylor et al. (1997) describe a back-analysis of the behaviour of Beliche Dam. Impounding effects were now considered. Materials were described by means of an elastoplastic critical-state model, and the analysis was performed in terms of effective stresses. A known distribution of pore water pressures (derived from piezometer data) was required to perform the analysis. Collapse effects induced by full saturation were introduced by means of a numerical algorithm, which reproduces a change in material properties (from a dry state to a saturated state). It requires two sets of constitutive parameters: one set for the dry material and a second one for the wet material. For the critical-state model adopted, a total of 14 model parameters were needed. Some settlement predictions are reproduced in Fig. 3(b). The 
predicted settlement values included in Fig. 3(b) correspond to full impoundment of the upstream shell and to a simulated impoundment (without uplift) of the downstream shell. The latter was introduced in an attempt to model the overall effect of rainfall events over an extended period (19881994).

The theses of Azevedo Filho (1990), Farias (1993), Pagano (1996) and Maranha (1997) include analyses of Beliche Dam using basically the procedure proposed by Naylor et al. (1989). Maranha das Neves (2002), in a comprehensive review of rockfill mechanics, describes the procedure followed by Mateus da Silva (1996). As wetting of an initially dry rockfill may imply that points initially at yield would remain outside the 'shrinking' yield surface, a viscoplastic algorithm is invoked to bring back the stress point to the 'current' yield surface. The current yield surface is located by assuming that material parameters evolve linearly from an initial dry state to a final saturated state. The construction and impoundment of Beliche Dam were also simulated by Mateus da Silva (1996) using the procedure outlined.

The analysis of zoned earth dams has also been approached from the perspective of unsaturated soil mechanics. The formal similarities between wetting tests performed on unsaturated low-plasticity soils and rockfill provide a justification for these approaches, which are, however, not supported by physically convincing evidence. Placing emphasis on volumetric deformations Alonso et al. (1988), and Alonso \& Batlle (1995) have presented several analyses of dam construction and impoundment. The mechanical analyses were performed in a fully coupled mode with the flow phenomena, and therefore transient flow boundary conditions could be properly introduced. Additional fully coupled unsaturated-like analysis of earth and rockfill dams, using suction as an additional independent stress variable and describing the unsaturated materials by means of elastoplastic models, has been described by Costa (2000) and Kogho (2003).

The question of the applicability of unsaturated soil analysis to rockfill behaviour was raised by Naylor et al. (1997). In the discussion included in their paper they state:

No attempt was made in the analysis to model the effects of partial saturation as, for example, has been proposed by Alonso et al. (1990). This effect is thought to be small in the rockfill...

The opinion that partial saturation has a small effect in the rockfill is probably based on a capillary interpretation of suction effects in granular materials. In fact, approximate calculations of capillary induced stresses in rockfill and gravels (Alonso, 2003) indicate that their absolute values are extremely small, and therefore their reduction (due to wetting) may hardly affect gravel or rockfill behaviour. However, the effects of partial saturation in rockfill should be approached from a different perspective, as discussed below.

\section{Aims of the paper}

In recent papers (Oldecop \& Alonso, 2001, 2002, 2003; Chávez \& Alonso, 2003), the effect of water on rockfill behaviour has been linked to fracture propagation phenomena. This underlying mechanism, which controls particle breakage, and the results of large-scale oedometer and triaxial tests on gravel-like aggregates, in which the relative humidity prevailing at the large voids of the specimens was controlled, led to the formulation of new constitutive models. They were formulated within the framework of hardening plasticity, and they offer a comprehensive description of several features of rockfill behaviour, including collapse phenomena. These developments bring the opportunity of performing more accurate and consistent analysis of rockfill structures. From this perspective, Beliche Dam offers an interesting case record, with the added advantage of being a case extensively analysed in the recent past. New elements for an improved understanding will hopefully be added. As mentioned before, a fundamental aspect of the behaviour of Beliche Dam is the rockfill collapse induced by partial, as well as full, wetting. Partial wetting, induced by rainfall, was shown to have the same relevance as full flooding. Most of the computational procedures used so far, uncoupled to water flow, are unable to handle this fundamental environmental factor. Beliche is not an isolated case in this respect. Justo \& Durand (2000) showed the close relationship between rainfall intensity and the acceleration of settlements experienced by different points inside the rockfill embankment of Martín Gonzalo Dam. Settlement plates reacted to strong rainfall events during a given period-within the first three years after the end of construction. Later, rainfall was not able to induce additional settlements. Similar behaviour was observed in dams such as Beliche (Fig. 3) or El Infiernillo (Marsal et al., 1976), and in large railway rockfill embankments (Soriano \& Sánchez, 1999).

In this paper, a coupled flow-deformation analysis of the history of construction, impoundment and the operational phase of Beliche Dam is presented. Due consideration will be given to rainfall, during both construction and subsequent phases. Model calculations will be compared with field measurements. The main source of experimental and field information was provided by Naylor et al. (1986, 1997). The paper is organised as follows. First, the elastoplastic models used for the description of dam materials will be introduced, paying special attention to the rockfill model and to the physical nature of model parameters. The results of oedometer and triaxial tests performed at the Laboratorio Nacional d'Engenheria Civil of Lisbon (LNEC) will be back-analysed in order to derive model parameters. Hydraulic parameters have been approximated on the basis of known identification data. Details of the coupled flow-mechanical analysis performed will then be given. Spatial distributions of some measured variables at some specific times (vertical and horizontal displacements, stresses) will be obtained and compared with measurements. Also, time records of settlements and horizontal displacements will be obtained and compared with actual measurements. Calculated stress paths at some specific points within the dam will be given, with the purpose of understanding the deformation phenomena observed in the structure.

An analysis was first conducted using the parameters derived directly from laboratory tests. This case represents the base case. Additional cases, modifying both the rockfill compressibility, to account for scale effects, and the rockfill permeability were also performed. Finally, the obtained results are discussed.

\section{CONSTITUTIVE MODELS}

Two different models were used to describe the behaviour of the dam core, a low-plasticity clay, and the rockfill shoulders. For the clay core, the model proposed by Alonso et al. (1990) (BBM: 'Barcelona Basic Model') is adopted. A summary of the basic relationships of this model is given in Table 1. The model for the rockfill shoulders (RM) is an extension of the compressibility model developed by Oldecop \& Alonso (2001), and it will be described in more detail here.

\section{Rockfill model for triaxial conditions}

Volumetric compressibility of rockfill is assumed to have two components, whose origins are a particle rearrangement 
Table 1. Basic relationships for constitutive models used in the analysis of Beliche Dam*

\begin{tabular}{|c|c|c|}
\hline & $\begin{array}{l}\text { Barcelona Basic Model (BBM) } \\
\text { (Alonso et al., 1990) }\end{array}$ & $\begin{array}{c}\text { Rockfill Model (RM) } \\
\text { (Compressibility part described in } \\
\text { Oldecop \& Alonso, 2001) }\end{array}$ \\
\hline $\begin{array}{l}\text { Isotropic elastoplastic } \\
\text { volumetric } \\
\text { deformation } \dagger\end{array}$ & $\mathrm{d} \varepsilon_{\mathrm{v}}=\frac{\lambda(s)}{1+e} \frac{\mathrm{d} p}{p}$ & $\begin{array}{l}\text { For } p \leqslant p_{\mathrm{y}} \Rightarrow \mathrm{d} \varepsilon_{\mathrm{v}}=\mathrm{d} \varepsilon_{\mathrm{v}}^{\mathrm{i}}=\lambda^{\mathrm{i}} \mathrm{d} p \\
\text { For } p>p_{\mathrm{y}} \Rightarrow \mathrm{d} \varepsilon_{\mathrm{v}}=\mathrm{d} \varepsilon_{\mathrm{v}}^{\mathrm{i}}+\mathrm{d} \varepsilon_{\mathrm{v}}^{\mathrm{d}}= \\
=\left[\lambda^{\mathrm{i}}+\lambda^{\mathrm{d}}(s)\right] \mathrm{d} p\end{array}$ \\
\hline $\begin{array}{l}\text { Volumetric } \\
\text { compressibility index } \dagger\end{array}$ & $\lambda(s)=\lambda(0)[(1-r) \exp (-\beta s)+r]$ & $\begin{array}{c}\lambda^{\mathrm{i}}+\lambda^{\mathrm{d}}(s) \\
\lambda^{\mathrm{d}}(s)=\lambda_{0}^{\mathrm{d}}-\alpha_{\mathrm{s}} \ln \left(\frac{s+p_{\mathrm{atm}}}{p_{\mathrm{atm}}}\right)\end{array}$ \\
\hline Hardening law & $\mathrm{d} p_{0}^{*}=\frac{(1+e) p_{0}^{*}}{\lambda(0)-\kappa} \mathrm{d} \varepsilon_{\mathrm{v}}^{\mathrm{p}}$ & $\mathrm{d} p_{0}^{*}=\frac{\mathrm{d} \varepsilon_{\mathrm{v}}^{\mathrm{p}}}{\lambda^{\mathrm{i}}-\kappa}$ \\
\hline & $\left(n^{*}\right)^{\frac{\lambda(0)-\kappa}{\lambda(s)-\kappa}}$ & For $p_{0}^{*} \leqslant p_{\mathrm{y}} \Rightarrow p_{0}(s)=p_{0}^{*}$ \\
\hline $\begin{array}{l}\text { Loading-collapse curve } \\
\text { (LC) }\end{array}$ & $p_{0}(s)=p^{\mathrm{c}}\left(\frac{p_{0}^{*}}{p^{\mathrm{c}}}\right)$ & For $p_{0}^{*}>p_{\mathrm{y}} \Rightarrow p_{0}(s)=p_{\mathrm{y}}+\frac{\left(\lambda^{\mathrm{i}}-\kappa\right)\left(p_{0}^{*}-p_{\mathrm{y}}\right)}{\lambda^{\mathrm{i}}+\lambda^{\mathrm{d}}(s)-\kappa}$ \\
\hline $\begin{array}{l}\text { Shear strength critical- } \\
\text { state parameter }\end{array}$ & $M(s)=M$ & $M(s)=M_{\text {dry }}-\left(M_{\text {dry }}-M_{\text {sat }}\right)\left(\frac{M_{\text {sat }}}{M_{\text {dry }}}\right)^{\frac{s}{10 p_{\text {atm }}}}$ \\
\hline $\begin{array}{l}\text { Tensile strength } \\
\text { parameter }\end{array}$ & \\
\hline Yield surface(triaxial) & \multicolumn{2}{|c|}{$F(p, q, s)=q^{2}-M^{2}\left[p+p_{\mathrm{s}}(s)\right]\left[p_{0}(s)-p\right]=0$} \\
\hline $\begin{array}{l}\text { Plastic potential } \\
\text { (triaxial) }\end{array}$ & \multicolumn{2}{|c|}{$G(p, q, s)=q^{2}-\alpha M^{2}\left[p+p_{\mathrm{s}}(s)\right]\left[p_{0}(s)-p\right]=0$} \\
\hline Creep strain & - & $\begin{array}{c}\frac{\mathrm{d} \varepsilon_{\mathrm{v}}}{\mathrm{d} t}=\frac{1}{\eta_{\mathrm{v}}} p \quad \frac{\mathrm{d} \varepsilon_{\mathrm{d}}}{\mathrm{d} t}=\frac{1}{3 \eta_{\mathrm{d}}} q \\
\frac{1}{\eta_{\mathrm{v}}}=\frac{\mu}{t}\left[1-\beta^{\mathrm{c}} \ln \left(\frac{s+p_{\mathrm{atm}}}{p_{\mathrm{atm}}}\right)\right] \\
\eta_{\mathrm{d}}=0 \cdot 1 \eta_{\mathrm{v}}\end{array}$ \\
\hline
\end{tabular}

* A common notation was used for equivalent parameters. Material constants are different for the soil and rockfill models. $\uparrow$ Suction $s$ refers to matric suction, in the case of BBM, and to total suction, in the case of RM.

and a particle breakage phenomenon. The second is highly dependent on the prevailing relative humidity (or, alternatively, the total suction, $s$ ) at the rockfill particles. The second mechanism is active beyond a threshold mean stress, $p_{\mathrm{y}}$. Isotropic compressibility is described by the following equations:

$$
\begin{array}{ll}
\mathrm{d} \varepsilon_{\mathrm{v}}=\lambda^{\mathrm{i}} \mathrm{d} p & \text { if } p \leqslant p_{\mathrm{y}} \\
\mathrm{d} \varepsilon_{\mathrm{v}}=\lambda^{\mathrm{i}} \mathrm{d} p+\lambda^{\mathrm{d}}(s) \mathrm{d} p & \text { if } p>p_{\mathrm{y}}
\end{array}
$$

where $\mathrm{d} \varepsilon_{\mathrm{v}}$ is the incremented volumetric strain, $p$ is the mean total stress, and $\lambda^{\mathrm{i}}$ and $\lambda^{\mathrm{d}}(s)$ are compressibility parameters. $\lambda^{\mathrm{d}}(s)$, which is made dependent on total suction, describes a deformation mechanism based on particle breakage, and it accounts for some macroscopic phenomena observed in rockfill testing: the compressibility of rockfill increases as the material is wetted, and the rockfill collapses, at constant confining stress, when the ambient relative humidity is increased. The superscript ' $\mathrm{d}$ ' in $\lambda^{\mathrm{d}}(s)$ alludes to the delayed nature of the particle breakage mechanisms.

An appropriate function for the clastic compressibility parameter $\lambda^{\mathrm{d}}(s)$ was found to be

$$
\lambda^{\mathrm{d}}(s)=\lambda_{0}^{\mathrm{d}}-\alpha_{\mathrm{s}} \ln \left(\frac{s+p_{\mathrm{atm}}}{p_{\mathrm{atm}}}\right)
$$

where $\lambda_{\mathrm{o}}^{\mathrm{d}}$ is the volumetric compressibility for saturated conditions and $\alpha_{\mathrm{s}}$ is a material parameter. The atmospheric pressure, $p_{\text {atm }}$, is introduced to avoid indeterminacies for saturated conditions $(s=0)$. $\lambda^{\mathrm{d}}(s)$ is restricted by $\lambda^{\mathrm{d}}(s) \geqslant 0$.

Rockfill elastic behaviour is characterised by two compressibility coefficients $\kappa$ and $\kappa_{\mathrm{s}}$, and a Poisson ratio, $\nu$. The compressibility coefficients $\kappa$ and $\kappa_{\mathrm{s}}$ are defined as follows:

$$
\begin{aligned}
& \mathrm{d} \varepsilon_{\mathrm{v}}^{\mathrm{e}}=\kappa \mathrm{d} p=\frac{\mathrm{d} p}{E} 3(1-2 v) \\
& \mathrm{d} \varepsilon_{\mathrm{v}}^{\mathrm{es}}=\kappa_{\mathrm{s}} \frac{\mathrm{d} s}{s+p_{\mathrm{atm}}}
\end{aligned}
$$

where the volumetric elastic strains $\mathrm{d} \varepsilon_{\mathrm{v}}^{\mathrm{e}}$ and $\mathrm{d} \varepsilon_{\mathrm{v}}^{\mathrm{es}}$ are induced by total stress and suction changes. Note that the elastic bulk modulus defined in equation 3(a) does not depend on the mean stress. The swelling stiffness coefficient $\kappa_{\mathrm{s}}$ is, in general, very small, except for expansive claystones and shales. As no evidence of rockfill expansion has been reported in the case of Beliche, a value of $\kappa_{\mathrm{s}}=0$ was adopted.

For isotropic conditions, the yield stress, $p_{0}$, was defined in Oldecop \& Alonso (2001) by the expression

$$
\begin{array}{ll}
p_{0}(s)=p_{0}^{*} & \text { if } p_{0}^{*} \leqslant p_{\mathrm{y}} \\
p_{0}(s)=p_{\mathrm{y}}+\frac{\left(\lambda^{\mathrm{i}}-\kappa\right)\left(p_{0}^{*}-p_{\mathrm{y}}\right)}{\lambda^{\mathrm{i}}+\lambda^{\mathrm{d}}(s)-\kappa} \text { if } p_{0}^{*}>p_{\mathrm{y}}
\end{array}
$$

where $p_{0}^{*}$ defines the position of the yield curve, and it was 
identified as the yield stress for a very dry rockfill. A simple volumetric hardening was proposed to follow the evolution of $p_{0}^{*}$ :

$$
\mathrm{d} p_{0}^{*}=\frac{\mathrm{d} \varepsilon_{\mathrm{v}}^{\mathrm{p}}}{\lambda^{\mathrm{i}}-\kappa}
$$

where the plastic volumetric strains, $\mathrm{d} \varepsilon_{\mathrm{v}}^{\mathrm{p}}=\mathrm{d} \varepsilon_{\mathrm{v}}-\mathrm{d} \varepsilon_{\mathrm{v}}^{\mathrm{e}}$, may be obtained through consistency conditions.

The model will now be extended to triaxial stress condition (stress variables $p=\left(\sigma_{1}+2 \sigma_{3}\right)_{3} ; q=\sigma_{1}-\sigma_{3}$ ) by means of a family of elliptical yield curves. The yield surface, $F$, in a space $(p, q, s)$ is now defined by

$$
F(p, q, s)=q^{2}-M^{2}(s)\left[p+p_{\mathrm{s}}(s)\right]\left[p_{0}(s)-p\right]=0
$$

This is a simple choice, although more elaborated constitutive models for rockfill have recently been proposed (Chávez \& Alonso, 2003). It will be shown later, by comparing model calculations with large-scale triaxial test results on compacted rockfill specimens, that the constitutive model based on the elliptical yield function provides satisfactory results. The effect of suction on rockfill strength is introduced through parameters $p_{\mathrm{s}}(s)$ and $M(s)$. Parameter $p_{\mathrm{s}}(s)$ provides an apparent cohesive intercept that serves to approximate the real non-linear strength envelopes found in testing. The dependence of the critical-state slope $M$ on $S$ also helps to introduce suction effects on rockfill limiting shear conditions. $p_{\mathrm{s}}(s)$ is simply defined as a linear function of suction:

$$
p_{\mathrm{s}}(s)=k_{\mathrm{s}} s
$$

where $k_{\mathrm{s}}$ is a material parameter.

As the available experimental data on rockfill often consist of tests performed on dry or flooded specimens, it was found convenient to define $M(s)$ in terms of two extreme values: $M_{\text {dry }}$ and $M_{\text {sat }}$. Often $M_{\text {dry }}$ corresponds to the relative humidity existing at the laboratory and $M_{\text {sat }}$ corresponds to saturated conditions. The transition from $M_{\text {sat }}$ to $M_{\text {dry }}$ takes place for an increase in suction from a zero value, when the specimen is saturated, to a very high value, typically a few tens or even hundreds of MPa for the relative humidity prevailing in laboratories. The following expression is proposed to model this variation:

$$
M(s)=M_{\text {dry }}-\left(M_{\text {dry }}-M_{\text {sat }}\right)\left(\frac{M_{\text {sat }}}{M_{\text {dry }}}\right)^{s / 10 p_{\text {atm }}}
$$

Rockfill behaves in a non-associated manner. Maintaining the model's simplicity, the modification of the yield function suggested for BBM will be adopted here, and a potential function $G$ is defined as follows:

$$
G(p, q, s)=q^{2}-\alpha M^{2}(s)\left[p+p_{\mathrm{s}}(s)\right]\left[p_{0}(s)-p\right]=0
$$

where $\alpha$ is a material parameter.

The relationships described have been collected in Table 1. The table helps to emphasise the formal similarities and differences between the RM and the BBM. Unlike the BBM, compressibility relations for the rockfill are described by linear functions relating strain and stress. The threshold stress $p_{\mathrm{y}}$ has no equivalent in the case of unsaturated soils. Note also that the hardening parameter for the case of rockfill, $p_{0}^{*}$, is defined for a very dry state, a concept that is not applicable to soils. An additional difference, important from a fundamental perspective, is that the suction term, $s$, has a definite mechanical meaning in the case of soils. It is generally accepted that, for low-plasticity unsaturated soils and silts, $s$ should be identified with the capillary or matric component of suction. The role of suction in the case of rockfill is different. Following the ideas of Oldecop \& Alonso (2001), suction controls the velocity of crack propagation in rockfill particles. Therefore no direct mechanical action should be assigned to the suction term in this case. It is a state variable externally controlled by boundary conditions and flow phenomena. The crack propagation velocity depends on the total energy of the water on propagating cracks, and therefore it is measured by the relative humidity or, alternatively, by the total suction. The distinction is probably not very significant in some applications such as dams, but it may prove significant in other situations in which the chemical composition of the water, which controls the osmotic component of total suction, is a relevant variable. In this paper osmotic effects are not considered, and total and matric suction become identical.

\section{Generalisation: the viscoplastic approach}

Equations (6) and (9) for the yield and potential functions may be generalised to a three-dimensional stress state by writing them in terms of the second invariant of the deviatoric stress tensor, $J_{2 \mathrm{D}}$, and the first invariant of the stress tensor, $J_{1}$, as follows:

$$
\begin{aligned}
& F\left(J_{1}, J_{2 \mathrm{D}}, s\right) \\
& \quad=3 J_{2 \mathrm{D}}-\frac{1}{9} M^{2}(s)\left(J_{1}+3 k_{\mathrm{s}} s\right)\left[3 p_{0}(s)-J_{1}\right]=0 \\
& G\left(J_{1}, J_{2 \mathrm{D}}, s\right) \\
& \quad=3 J_{2 \mathrm{D}}-\frac{1}{9} \alpha M^{2}(s)\left(J_{1}+3 k_{\mathrm{s}} s\right)\left[3 p_{0}(s)-J_{1}\right]=0
\end{aligned}
$$

A viscoplastic formulation offers computational advantages (Zienkiewicz \& Cormeau, 1974; Zienkiewicz \& Taylor, 2000), which proved to be of considerable help in the dam analysis reported in this paper. This is especially interesting in geotechnical problems because the viscoplastic approach provides a unique solution, and it is used as a regularising procedure. Collapse behaviour can be viewed as a softening process (the triaxial tests included in this paper are a good illustration in this regard), and this behaviour introduces numerical difficulties. In some cases instability occurs because collapse concentrates at isolated elements, while others in the vicinity experience an induced stress relaxation, and they revert to elastic conditions. This phenomenon complicates the modelling of generalised collapse. The viscoplastic approach helps in this regard because it homogenises the spatial distribution of collapse strains. It must be added that one can always ensure a solution as close as necessary to the 'true' elastoplastic solution by increasing sufficiently the fluidity parameter of the viscoplastic formulation (see below).

The preceding set of constitutive relations was cast in the form proposed by Perzyna (1966). Total strain rates $(\dot{\boldsymbol{\varepsilon}})$ are calculated as a sum of elastic $\left(\dot{\boldsymbol{\varepsilon}}^{\mathrm{e}}\right)$ and viscoplastic components $\left(\dot{\boldsymbol{\varepsilon}}^{\mathrm{vp}}\right)$ :

$$
\dot{\boldsymbol{\varepsilon}}=\dot{\boldsymbol{\varepsilon}}^{\mathrm{e}}+\dot{\boldsymbol{\varepsilon}}^{\mathrm{vp}}
$$

The viscoplastic component is computed through

$$
\dot{\boldsymbol{\varepsilon}}^{\mathrm{vp}}=\Gamma\langle\phi(F)\rangle \frac{\partial G}{\partial \sigma}
$$

where $\Gamma$ is a fluidity parameter and $\langle\phi(F)\rangle$ is a flow function defined as

$$
\begin{aligned}
\langle\phi(F)\rangle=\phi(F) & \text { if } F>0 \\
\langle\phi(F)\rangle=0 & \text { if } F \leqslant 0
\end{aligned}
$$


A usual expression for the flow function $\phi$ is (Perzyna, 1966)

$$
\phi(F)=\left(\frac{F}{F_{0}}\right)^{N}
$$

where $F_{0}$ is a reference stress to normalise $F$. The viscoplastic parameters $\Gamma=100 \mathrm{~s}^{-1}$ and $N=5$ have been chosen in order to obtain a solution as close as possible to plasticity: that is, deformations are not delayed in time. Furthermore, the viscoplastic contribution is fast compared with the creep contribution described below. The time dependence appears in the viscoplastic contribution as a result of suction or stress changes in time only, but not of delayed deformations. Another advantage of the viscoplastic approach is that an implicit scheme of integration can be easily used.

Plastic strains are calculated as the integral of the viscoplastic strain rates in a time interval. Total strains are computed as

$$
\begin{aligned}
\Delta \boldsymbol{\varepsilon} & =\Delta \boldsymbol{\varepsilon}^{\mathrm{e}}+\Delta \boldsymbol{\varepsilon}^{\mathrm{p}}=\Delta \boldsymbol{\varepsilon}^{\mathrm{e}}+\Delta t \dot{\boldsymbol{\varepsilon}}^{\mathrm{vp}} \\
& =\mathbf{D}_{\mathrm{e}}^{-1} \boldsymbol{\Delta} \boldsymbol{\sigma}+\Delta t\left[\Gamma\langle\phi(F)\rangle \frac{\partial G}{\partial \boldsymbol{\sigma}}\right]^{k+\theta} \\
& =\mathbf{D}_{\mathrm{e}}^{-1} \boldsymbol{\Delta} \boldsymbol{\sigma}+\Lambda\left[\frac{\partial G}{\partial \boldsymbol{\sigma}}\right]^{k+\theta}
\end{aligned}
$$

where $\Delta t=t^{\mathrm{k}+1}-t^{\mathrm{k}}$ is the time increment in which the strain increment is calculated, and the superscript $k+\theta$ indicates that the viscoplastic strain rate is calculated at an intermediate time defined as $t^{\mathrm{k}+\theta}=t^{\mathrm{k}}(1-\theta)+t^{\mathrm{k}+1} \theta$. The fully implicit approach is used here, and this implies $\theta=1$. Note that the term $\Delta t[\Gamma\langle\phi(F)\rangle]$ is formally equivalent to a plastic multiplier, $\Lambda$.

\section{Creep behaviour of rockfill}

Long-term deformation records of rockfill structures (Sowers et al., 1965; Sherard \& Cooke, 1987) show the significant creep behaviour of rockfill. The underlying mechanism of subcritical crack propagation in stressed particles provides a physical explanation for the observed macroscopic creep behaviour. Oldecop \& Alonso (2002) analysed long-term records of compacted gravel specimens of quartzitic shale tested under oedometric conditions and varying relative humidity. The strain-time records were interpreted in terms of a creep coefficient, $\lambda^{t}$, defined in a classical manner:

$$
\lambda^{t}=\frac{\mathrm{d} \varepsilon_{\mathrm{v}}}{\mathrm{d}(\ln t)}
$$

It was found that $\lambda^{\mathrm{t}}$ depends on confining stress and on the prevailing total suction, as shown in Fig. 4. For an extended range of stress and suction values, $\lambda^{t}$ depends linearly on confining stress and on the logarithm of the applied suction. The second dependence is illustrated in Fig. 5, where the creep coefficient $\lambda^{t}$ (represented in Fig. 4) is plotted in terms of $\ln (s)$ for a vertical confining stress $\sigma_{\mathrm{v}}=1 \mathrm{MPa}$. The creep rate decreases with increasing suction. Presumably a zero creep rate may be obtained for an essentially dry environment, but this limiting condition was not found in the experiments performed. Based on these findings, the following strain rate equation is proposed for the volumetric component of the long-term creep of rockfill:

$$
\dot{\varepsilon}_{\mathrm{v}}^{\mathrm{c}}=\frac{\mathrm{d} \varepsilon_{\mathrm{v}}^{\mathrm{c}}}{\mathrm{d} t}=\frac{\lambda_{t}(p, s)}{t}=\frac{1}{\eta_{\mathrm{v}}(s, t)} p
$$

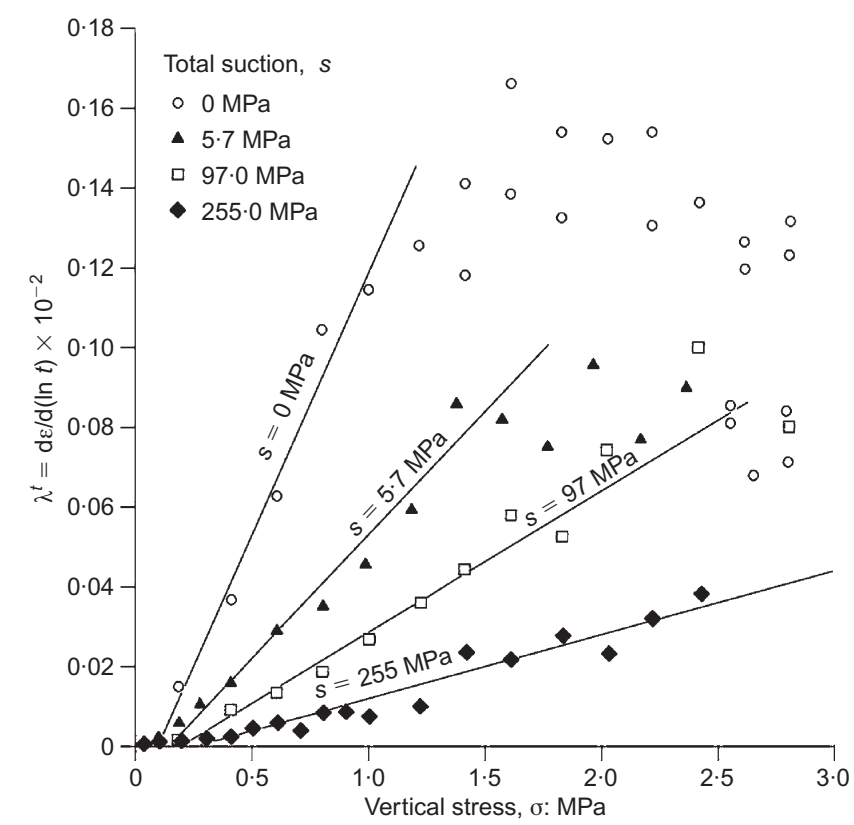

Fig. 4. Time-dependent compressibility index, $\lambda^{t}$, measured in oedometer tests performed on compacted gravel of a quartzitic shale (after Oldecop \& Alonso, 2002)

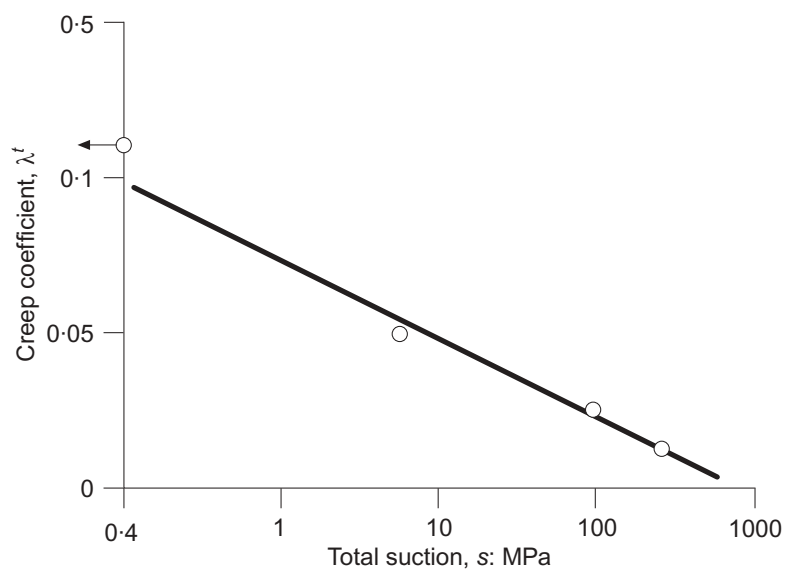

Fig. 5. Variation of $\lambda^{t}$ with suction for vertical stress $\sigma_{\mathrm{v}}=$ $1 \mathrm{MPa}$ (plot based on data represented in Fig. 4)

where the stress dependence is assumed to be linear, and $\eta_{\mathrm{v}}$ is a viscosity coefficient for volumetric creep given by

$$
\frac{1}{\eta_{\mathrm{v}}(s, t)}=\frac{\mu}{t}\left[1-\beta^{\mathrm{c}} \ln \left(\frac{s+p_{\mathrm{atm}}}{p_{\mathrm{atm}}}\right)\right]
$$

where $\mu$ and $\beta^{\text {c }}$ are constitutive parameters. The values $\mu=$ $0.0012 \mathrm{MPa}^{-1}$ and $\beta^{\mathrm{c}}=0.083$ provide an accurate representation of the creep data given in Fig. 4 for $\sigma_{\mathrm{v}}<1 \mathrm{MPa}$. These values were used in the analysis of Beliche Dam.

No equivalent experimental information was found for the deviatoric creep. A similar expression for the deviatoric creep is tentatively proposed here:

$$
\dot{\varepsilon}_{\mathrm{d}}^{\mathrm{c}}=\frac{\mathrm{d} \varepsilon_{\mathrm{d}}^{\mathrm{c}}}{\mathrm{d} t}=\frac{1}{3 \eta_{\mathrm{d}}(s, t)} q
$$

where $\eta_{\mathrm{d}}$ is probably related to $\eta_{\mathrm{v}}$. In fact, it is proposed that $\eta_{\mathrm{d}}$ will be a fraction of $\eta_{\mathrm{v}}$ :

$$
\eta_{\mathrm{d}}=a \eta_{\mathrm{v}}
$$

in order to maintain simplicity in the model. A small value $a=0 \cdot 1$ was adopted in the calculations reported below. 
Under general stress conditions, creep rates will be calculated through a general viscoelastic equation:

$$
\dot{\boldsymbol{\varepsilon}}^{\mathrm{c}}=\frac{1}{2 \eta_{\mathrm{d}}}(\boldsymbol{\sigma}-p \mathbf{I})+\frac{1}{3 \eta_{\mathrm{v}}} p \mathbf{I}
$$

where volumetric and deviatoric viscosities have already been defined, and $\mathbf{I}$ is the identity matrix.

In the generalised constitutive model rockfill, strain rates are calculated as the sum of three contributions-elastic, viscoplastic and long-term (or secondary) — as follows:

$$
\dot{\boldsymbol{\varepsilon}}=\dot{\boldsymbol{\varepsilon}}^{\mathrm{e}}+\dot{\boldsymbol{\varepsilon}}^{\mathrm{vp}}+\dot{\boldsymbol{\varepsilon}}^{\mathrm{c}}
$$

Expressions for the three contributions have already been given. Material parameters have been collected in Table 2 .

\section{FINITE ELEMENT MODEL}

The analysis of the dam was performed with the finite element code CODE_BRIGHT, developed at the Department of Geotechnical Engineering of UPC. The code solves simultaneously, in a monolithic manner, the balance equations for heat transfer, water flow and air flow, as well as the mechanical equilibrium equations. It is formulated in terms of two independent stress variables: the net stress (excess of total stress over air pressure), and suction or difference between air and water pressures. The formulation of the code and its numerical implementation are described in Olivella et al. (1994, 1996). A detailed description of the code is given in DIT-UPC (2002). Available in the current version of the code are a few mechanical constitutive models (linear and non-linear elasticity, viscoelasticity and viscoplasticity for saline and granular materials, BBM for unsaturated soils, and others). The viscoelastoplastic model for rockfill materials described before was also introduced in CODE_BRIGHT, in order to analyse rockfill structures.

The basic transport and deformation phenomena mentioned can be activated independently when a given problem is solved. For the analysis of Beliche Dam, only the coupled flow and deformation relationships were simultaneously solved.

Material parameters were approximated by means of a back-analysis of the large-diameter tests performed at the LNEC. Test results were interpreted through CODE_ BRIGHT, as reported in the next section. Laboratory results on foundation materials were also interpreted, to find the corresponding constitutive parameters. Flow-related parameters were not reported in the available data, but they were approximated on the basis of indirect information (grain size distributions, plasticity) and past experience.

\section{DETERMINATION OF MATERIAL PARAMETERS}

Rockfill materials for the inner and outer shell were tested in a large-diameter oedometer $($ dia. $=500 \mathrm{~mm}$ ) and triaxial $($ dia. $=300 \mathrm{~mm})$ cells. The gradation of the material tested was scaled down by making the specimen cumulative grain size distributions parallel to the gradation curve of the in situ rockfill material. Tests were performed on a dry material (presumably equilibrated with the relative humidity prevailing in the laboratory). At some stage during the triaxial tests, specimens were flooded, although the applied vertical strain rate was maintained during the sample inundation and subsequent straining.

In order to interpret these tests, specimens were treated as a boundary value problem. Stress, strain and flow conditions were applied at the specimen's boundaries as required. Flowrelated properties are therefore required to perform calculations. A common water retention curve for the two types of rockfill (inner and outer shell) was used. It is shown in Fig. 6. The curve is similar to the retention curve measured in compacted specimens of schist reported in Oldecop \& Alonso (2001). It shows two distinct parts, which reflect the pore structure of a rockfill material. The relatively large voids between rock particles, which provide most of the pore volume, become empty for a very small suction (0.0001$0.001 \mathrm{MPa}$ in the figure). All the remaining water is then stored within the rock particles, which exhibit a strong resistance to becoming unsaturated, as suction increases, because of the small size of the rock pores. In this way, a bimodal shape characterises the water retention behaviour of rockfill. For the low-plasticity clay used in the core, the water retention curve shown in Fig. 6 was adopted in calculations. An air entry value close to $0 \cdot 1 \mathrm{MPa}$ was assumed in this case.

Hydraulic conductivities of all dam materials are described by the expression

$$
K=k \frac{\rho_{\mathrm{w}} g}{\mu_{\mathrm{w}}} K_{\mathrm{r}}\left(S_{\mathrm{r}}\right)
$$

\begin{tabular}{|c|c|c|c|c|}
\hline \multirow[t]{2}{*}{ Definition of parameter } & \multirow[t]{2}{*}{ Symbol } & \multirow[t]{2}{*}{ Units } & \multicolumn{2}{|c|}{$\begin{array}{c}\text { Base case for Beliche } \\
\text { Dam }\end{array}$} \\
\hline & & & Inner shell & Outer shell \\
\hline \multicolumn{5}{|l|}{ Elastic behaviour } \\
\hline Elastic modulus & $E$ & $\mathrm{MPa}$ & 150 & 180 \\
\hline Poisson's ratio & $v$ & - & $0 \cdot 3$ & $0 \cdot 3$ \\
\hline \multicolumn{5}{|l|}{ Plastic behaviour } \\
\hline Plastic virgin instantaneous compressibility & $\left(\lambda^{\mathrm{i}}-\kappa\right)$ & - & $0 \cdot 025$ & 0.01 \\
\hline Virgin clastic compressibility for saturated conditions & $\lambda_{0}^{\mathrm{d}}$ & - & $0 \cdot 028$ & 0.01 \\
\hline Parameter to describe the rate of change of clastic compressibility with total suction & $\alpha_{\mathrm{s}}$ & _- & $0 \cdot 010$ & $0 \cdot 003$ \\
\hline Slope of critical-state strength envelope for dry conditions & $M_{\text {dry }}$ & - & $1 \cdot 75$ & $1 \cdot 90$ \\
\hline Slope of critical-state strength envelope for saturated conditions & $M_{\mathrm{sat}}$ & _ & $1 \cdot 30$ & 1.80 \\
\hline Parameter that controls the increase in cohesion with suction & $k_{\mathrm{s}}$ & - & 0 & 0 \\
\hline Threshold yield mean stress for the onset of clastic phenomena & $p_{\mathrm{y}}$ & $\mathrm{MPa}$ & 0.01 & 0.01 \\
\hline Parameter that defines the non-associativeness of plastic potential & $\alpha$ & - & $0 \cdot 3$ & $0 \cdot 3$ \\
\hline \multicolumn{5}{|l|}{ Creep behaviour } \\
\hline Creep coefficient for saturated conditions & $\mu$ & $\mathrm{MPa}^{-1}$ & $0 \cdot 0012$ & $0 \cdot 0012$ \\
\hline Parameter that controls the influence of suction on creep rate & $\beta^{\mathrm{c}}$ & - & $0 \cdot 083$ & $0 \cdot 083$ \\
\hline \multicolumn{5}{|l|}{ Initial state for dam model } \\
\hline Initial suction & $s_{0}$ & $\mathrm{MPa}$ & 20 & 20 \\
\hline Initial mean yield stress & $p_{0}^{*}$ & MPa & $0 \cdot 02$ & $0 \cdot 02$ \\
\hline
\end{tabular}

where $k$ is the intrinsic permeability $\left(\mathrm{m}^{2}\right) ; \mu_{\mathrm{w}}$ is the

Table 2. Mechanical parameters for rockfill 


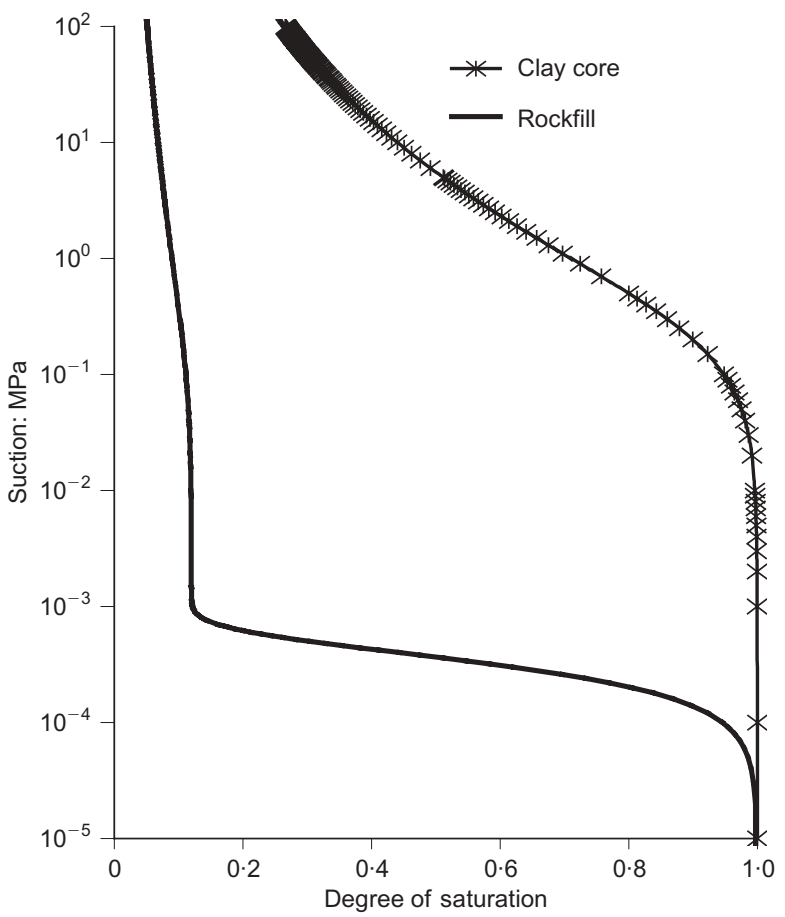

Fig. 6. Water retention curves for rockfill material and clay core

viscosity of the fluid (for water, $\mu_{\mathrm{w}}=0.001 \mathrm{~Pa} \mathrm{~s}$ ); $\rho_{\mathrm{w}}$ is the density of the fluid (for water, $\rho_{\mathrm{w}}=1000 \mathrm{~kg} / \mathrm{m}^{3}$ ); and $g$ is the acceleration due to gravity. The intrinsic permeability depends on the porosity and fabric of the porous material. The selected values are included in Table 3. Parameter $K_{\mathrm{r}}\left(S_{\mathrm{r}}\right)$, the relative permeability, introduces the effect of partial saturation. $K_{\mathrm{r}}$ varies between 0 (dry soil) and 1 (saturated soil), and it is usually expressed as a non-linear function of the degree of saturation $\left(S_{\mathrm{r}}\right)$. The functions used are represented in Fig. 7. A relative permeability defined as a power law of the degree of saturation has been considered. Exponent values of 3 for the clay core and foundation soil and 10 for the rockfill are used. In the case of the rockfill, the relative permeability starts to decrease below 1 when the degree of saturation becomes smaller than $0 \cdot 3$. It was assumed that, for degrees of saturation in excess of $0 \cdot 3$, water can circulate freely through the rockfill macropores. Mualem (1976) proposed a 'consistent' methodology to derive the relative permeability function on the basis of the water retention curve. The method proposed by Mualem, verified for sandy soils, leads to the theoretical curve shown in Fig. 7. The power law adopted was close to this theoretical law, and it is considered more suitable for rockfill conditions.

Oedometer tests were simulated by means of a onedimensional mesh. A constant displacement rate was applied to the upper boundary, and stresses were calculated. Triaxial specimens were simulated by means of an axisymmetric mesh, defined by 32 linear quadrilateral elements. The

Table 3. Initial void ratio and intrinsic permeability adopted in calculations

\begin{tabular}{l|c|c}
\hline Material & $\begin{array}{c}\text { Initial void } \\
\text { ratio, } e_{0}\end{array}$ & $\begin{array}{c}\text { Intrinsic } \\
\text { permeability, } \\
k: \mathrm{m}^{2}\end{array}$ \\
\hline Rockfill shells & 0.538 & $2 \times 10^{-11}$ \\
Clay core & 0.786 & $8 \times 10^{-15}$ \\
Foundation soil & 0.428 & $3 \times 10^{-12}$ \\
\hline
\end{tabular}

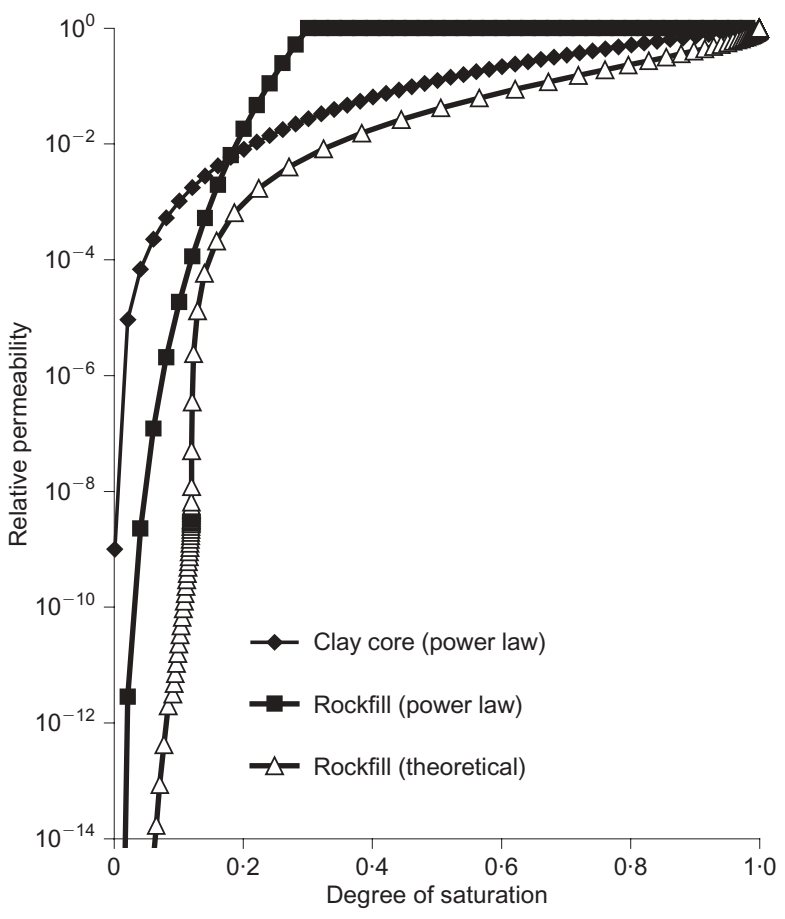

Fig. 7. Relative permeability functions for rockfill and clay core

confining stress was applied against the lateral boundaries, and a constant vertical displacement rate was applied to the upper boundary. Stresses were computed at this boundary. For the dry stage of tests, a constant high suction, which represents the laboratory conditions, was maintained in the specimen, and the boundaries were assumed to be impervious. Flooding was simulated by converting the lower boundary into a zero-suction boundary.

Inner schist shell

Measured and simulated responses for the oedometer and triaxial tests are shown in Figs 8 and 9. Compressibility parameters (instantaneous, clastic) (as well as an approximation of the elastic modulus) could be derived from the oedometer results. A comparison of the calculated and measured responses of the simulated triaxial test is represented in Fig. 9.

The stress-suction paths actually experienced by the specimens are not particularly simple. This is illustrated in Fig. 10, in a $(p, q, s)$ space. The compacted specimen is initially loaded isotropically under very dry conditions (point A). The specimen is then loaded vertically at constant

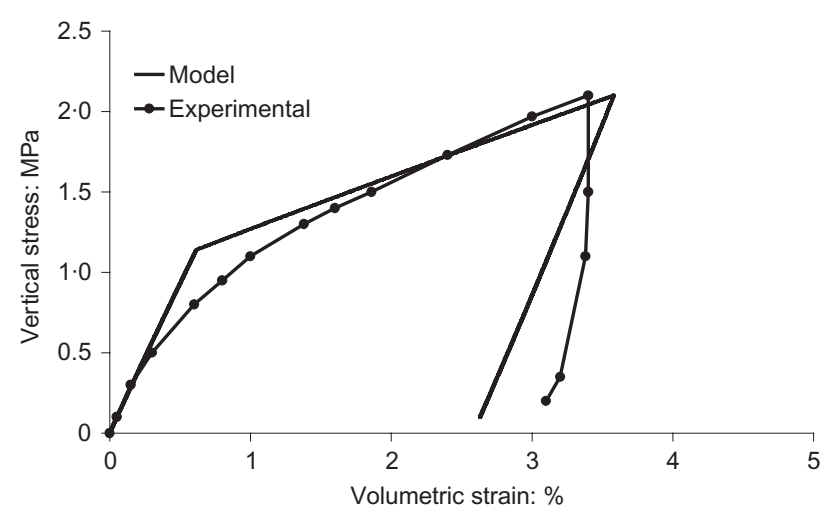

Fig. 8. Oedometer test on compacted schists from inner shell 


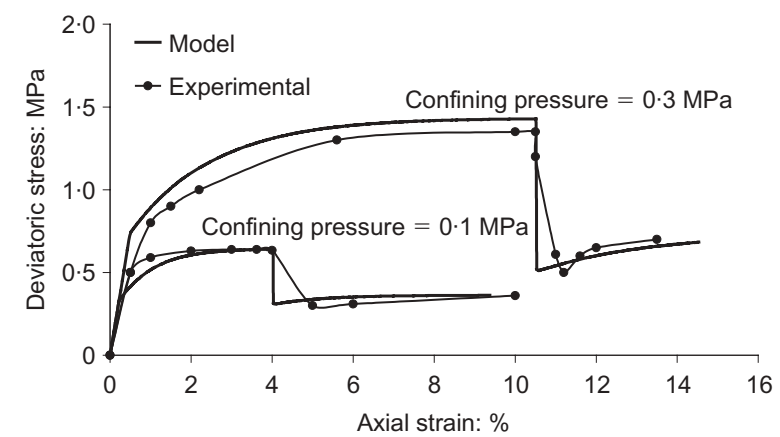

(a)

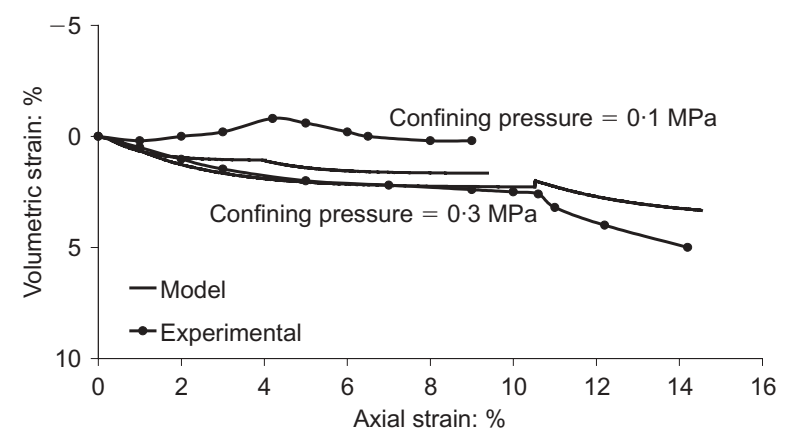

(b)

Fig. 9. Triaxial tests on compacted schists from inner shell: (a) deviatoric stress-strain curves; (b) volumetric-axial strain curves

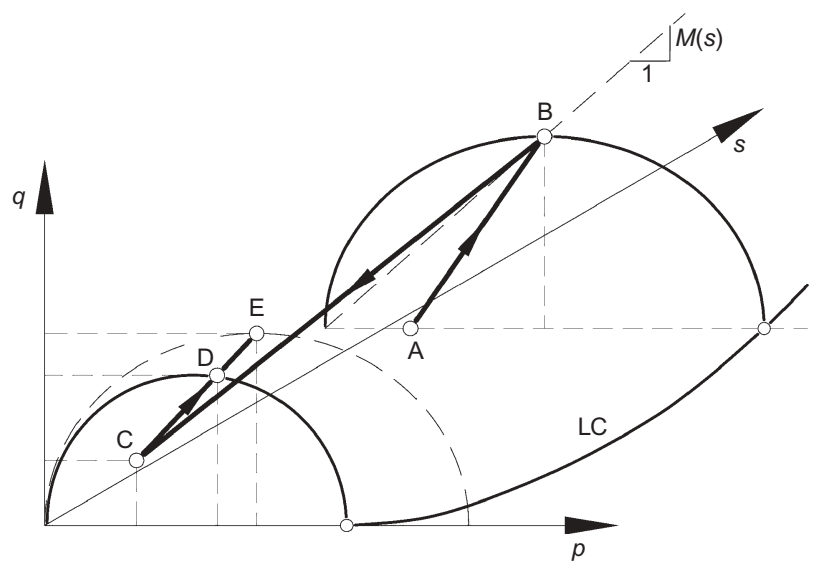

Fig. 10. Sketch showing stress-suction path applied in triaxial tests initially dry and later flooded when limiting conditions are reached

suction until the limiting condition (point B) is reached. Then it was flooded, while the constant rate of vertical strain is maintained. The volumetric collapse induces a sudden loss of vertical stress, and, at the same time, the suction is reduced to zero. Point $\mathrm{C}$ is reached. The position of point $\mathrm{C}$ depends on the rate of applied vertical displacement and on the specimen's permeability: it cannot be determined on the basis of the constitutive equation alone. Once at zero suction, the yield envelope experiences a reduction in size. As the vertical strain rate is maintained, the specimen starts resisting again along the loading path and eventually reaches a new yield condition at point $\mathrm{D}$, and a final limiting state at point E. These triaxial tests provide direct information on the strength envelope for dry and saturated conditions $\left(M_{\text {dry }}\right.$, $M_{\text {wet }}$ ), and on the elastic parameters. The volumetric behav- iour, reproduced in Fig. 9(b), provides an indication of the value of the $\alpha$ parameter defining the plastic potential. For low confining stresses, dilatancy is underestimated by the model. This is a feature of the constitutive model used, which is not well suited to reproducing the observed dilatancy behaviour in samples exhibiting a ductile response in shear.

Rockfill specimens for laboratory tests were prepared by compacting the material in thin layers to obtain uniform samples (Naylor et al., 1986). In order to simulate the oedometer and triaxial tests, a significant preconsolidation effective mean stress, associated with compaction, was used in the model ( $p_{0}^{*}=0.9 \mathrm{MPa}$ for both inner and outer shell). A non-linear elastic model would facilitate the modelling of the tests, and would require a lower apparent preconsolidation stress. However, for the dam model, yielding was assumed to be active at a low stress $\left(p_{0}^{*}=0.02 \mathrm{MPa}\right.$ for both shells). It is believed that yield conditions in the field, which include particle breakage, especially for the lightly compacted inner shell in $1 \mathrm{~m}$ thick layers, start immediately after compaction.

The parameters used to reproduce the tests have been collected in Table 2. They will be considered as the base case.

\section{Outer greywacke shell}

The results of the simulations performed and a comparison with actual test measurements are shown in Figs 11 and 12. The greywacke rockfill is substantially stiffer than the lightly compacted schist, as the derived elastic and plastic compressibility parameters collected in Table 2 indicate. Strength is also higher for the greywacke. The model captures reasonably well the measured stress-strain curves under dry conditions, the transient loss of deviatoric stress associated with flooding, and the final recovery of strength under wet conditions. Compression volumetric strains are overpredicted (Fig. 12(b)), however, especially for low confining stresses when dilatancy effects seem to dominate. The identified clastic compressibility of the outer material $\left(\lambda_{0}^{\mathrm{d}}=\right.$ 0.01) is small compared with the value found for the inner schist. This implies that relative humidity changes will have a limited effect on computed collapse in this material.

The analysed experimental data are not sufficient to discriminate accurately among the different model parameters. In particular, oedometer tests, which would include a suction reduction stage (ideally under suction control), are required for a precise determination of the parameters $\left(\lambda^{\mathrm{i}}-\right.$ $\kappa), \lambda_{0}^{\mathrm{d}}$ and $\alpha_{\mathrm{s}}$. Suction control also helps in the interpretation of triaxial testing. Nevertheless, the set of large-diameter tests performed at LNEC provided sufficient data to derive model parameters with an acceptable degree of confidence.

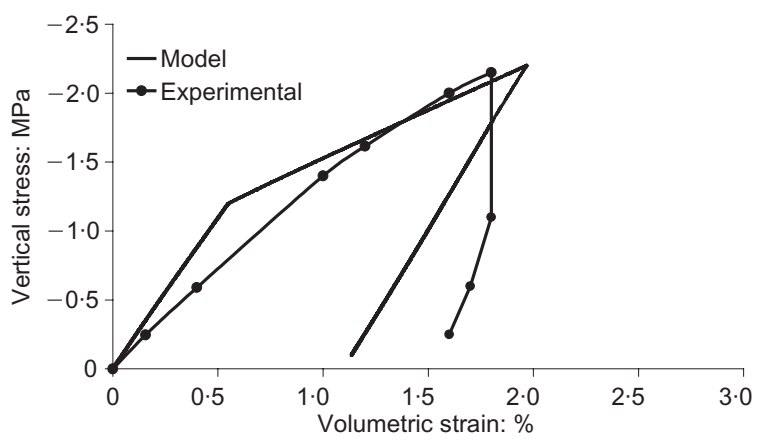

Fig. 11. Oedometer test on compacted greywacke from outer shell 


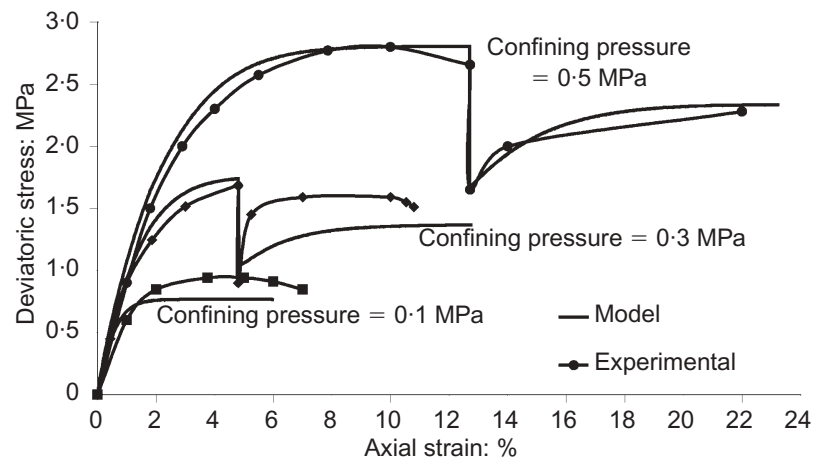

(a)

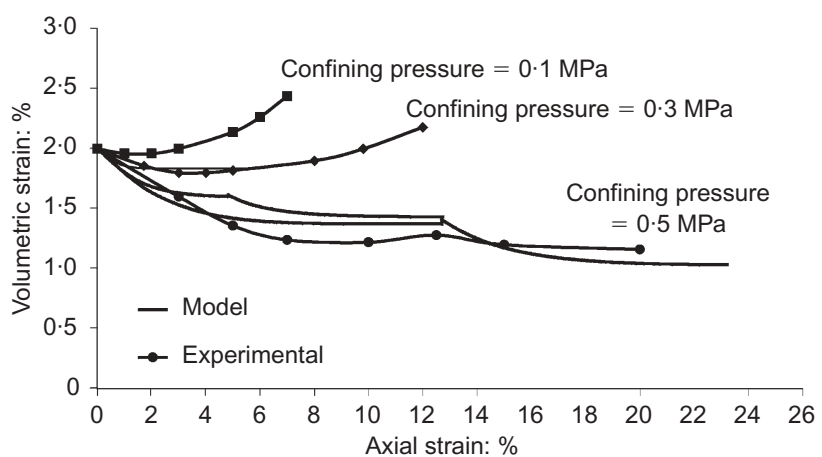

(b)

Fig. 12. Triaxial tests on compacted greywacke from outer shell: (a) deviatoric stress-strain curves; (b) volumetric-axial strain curves

Clay core and foundation soil

The core material was described in Naylor et al. (1986, 1997) as low-plasticity clay. Grain size distributions show that it had a dominant sand fraction. Triaxial tests on $100 \mathrm{~mm}$ diameter specimens were performed 'undrained' on compacted samples having water contents centred at the optimum. No information concerning the initial suction of these specimens is available. Experience with low-plasticity clays and clayey sands indicates that suction at the optimum Proctor may be of the order of $0.5 \mathrm{MPa}$ (Gens et al., 1995; Suriol et al., 2002). The degree of saturation associated with this suction in the water retention curve adopted (Fig. 6) is $0 \cdot 80$, which is also a reasonable value for low-plasticity clays. Therefore the simulation of the available triaxial and oedometer tests of the core was performed on unsaturated specimens, and a constant suction $s=0.5 \mathrm{MPa}$ was applied. In this case, the BBM was the constitutive model selected. A comparison of test results and model calculations is given in Figs 13 and 14. The set of parameters used in the calculations is given in Table 4.

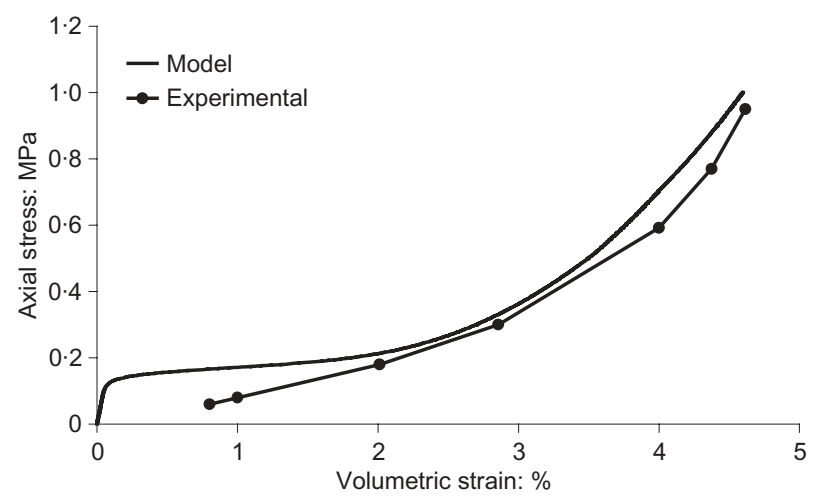

Fig. 13. Oedometer test on compacted clay core material

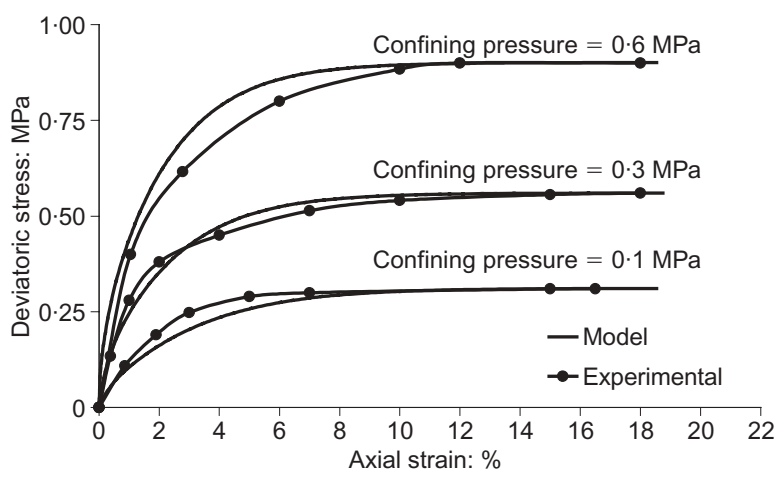

(a)

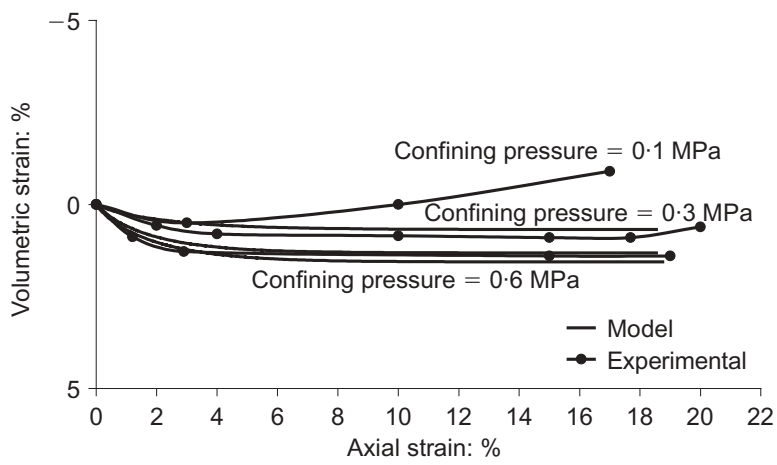

(b)

Fig. 14. Triaxial tests on compacted clay core material: (a) deviatoric stress-vertical strain curves; (b) volumetric-axial strain curves

The core of the dam was founded directly on moderately weathered schists (Fig. 1), which were assumed rigid in computations. The valley alluvial deposits (sand and gravels of medium density with silt inclusions) were excavated as shown in Fig. 1.

Naylor et al. (1986) also provided the results of oedometer and triaxial tests, performed on the saturated foundation soils (Figs 15 and 16). Foundation soils were simulated by means of a Cam clay model. The preconsolidation effective mean stress for the clay core and the foundation material was $0.02 \mathrm{MPa}$ and $0.50 \mathrm{MPa}$ respectively. The set of parameters given in Table 4 provides an acceptable representation of test results. The foundation material plays a minor role in the analysis performed, which concerns mainly the dam materials.

\section{DEFINITION OF THE COMPUTATIONAL MODEL}

The complete history of the dam construction and operation has been simulated. It includes the initial construction of the dam, the evolution of water level in the reservoir, and the history of rainfall. The reservoir level and rainfall intensity were given in Fig. 3(a). A somewhat simplified variation of water level and rainfall, based on monthly averages (see Fig. 17) was considered in the analysis.

The discretised dam geometry is shown in Fig. 18. Fig. 18(a) shows the construction layers and the four materials considered: foundation soil, clay core, inner rockfill, and outer rockfill. The geometry of the small dam constructed upstream in order to divert the river was included into the discretisation of the outer shell. The dam was discretised by means of quadratic triangular six-noded elements (Fig. 18(b)). Nodes have three degrees of freedom (water pressure, horizontal and vertical displacement).

Construction was simulated by adding layers to an initial 
Table 4. Parameters for the mechanical models used for the clay core and the foundation soil

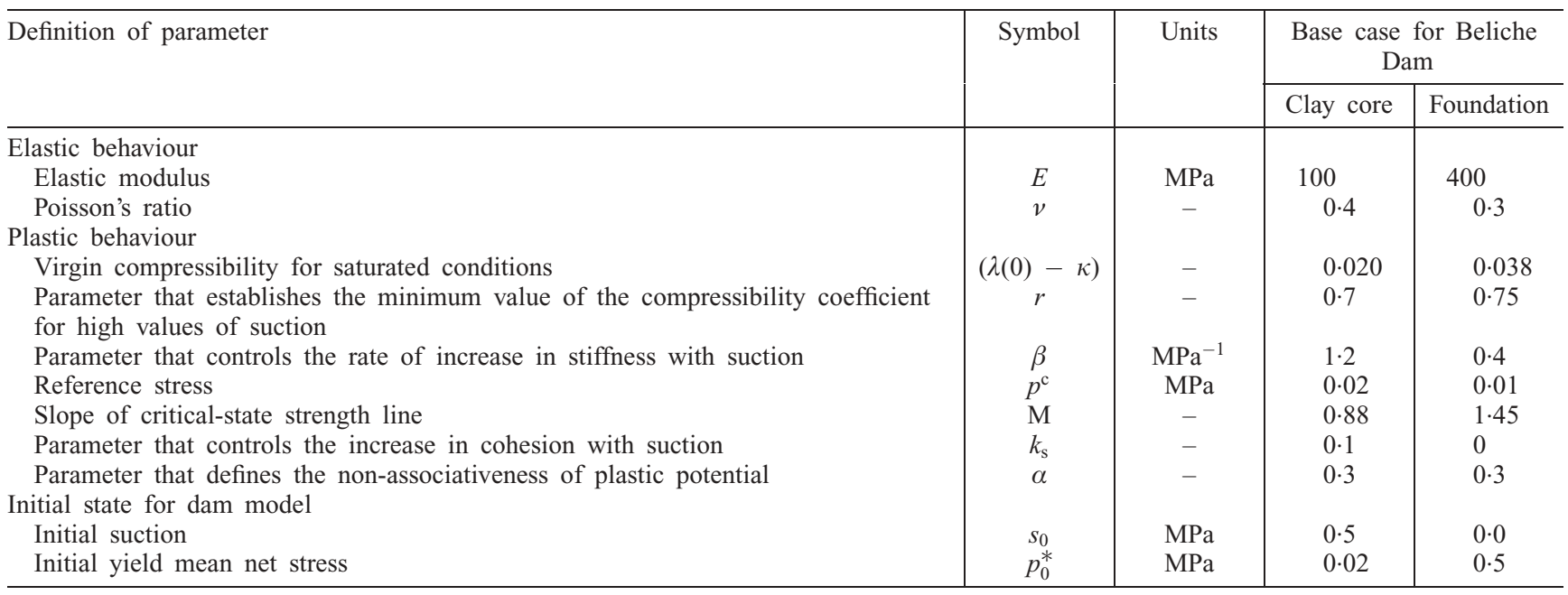

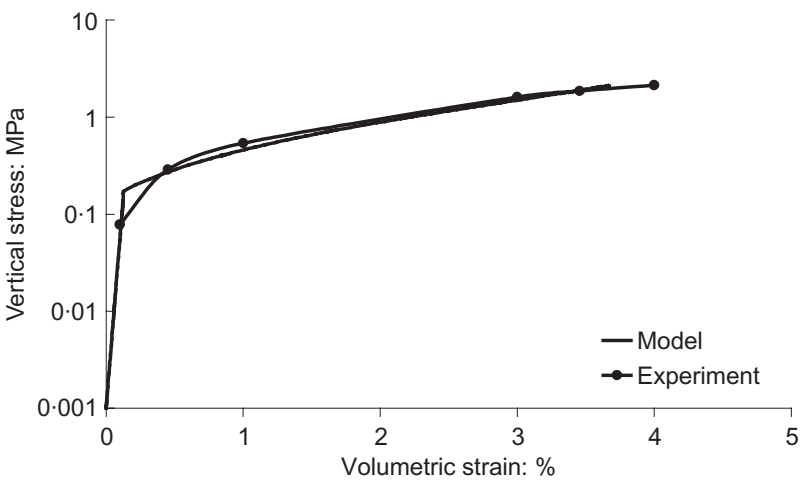

Fig. 15. Oedometer test on foundation soil

geometry, which represents the natural foundation soil. The weight of each layer was applied in a ramp manner so that the layer reached its full weight at the end of the specified construction time. The mesh shown in Fig. 18(b) is sufficiently dense to achieve a good accuracy. The process of layered construction is described in Potts \& Zdravkovic (2001). The construction process usually involves a reduction in material stiffness. In the present case, the new layers have a low stiffness due to the low initial preconsolidation stress associated with its own weight, and therefore no reduction in layer stiffness was applied.

Horizontal and vertical displacements were fixed at the lower plane of the model, which was considered impervious. Horizontal displacements were also fixed to zero on the upstream and downstream vertical boundaries of the foundation soil. Vertical displacements were set free at these lateral boundaries. The downstream vertical boundary of the foundation soil was provided with a 'seepage' hydraulic condition, which allows water outflow when water pressure reaches a value of $-0.2 \mathrm{MPa}$. For lower water pressures, no flow is allowed. This is a procedure to simulate certain outflow at the downstream end and to avoid unrealistic accumulation of water in the discretised domain. This boundary condition is equivalent to considering that the phreatic surface remains below the discretised domain in the downstream zone.

Rainfall was introduced as a flux boundary condition on the current exposed surface of the dam geometry. The imposed fluxes are given in Fig. 17 as a function of time. The rainfall inflow is removed from the surface of a given

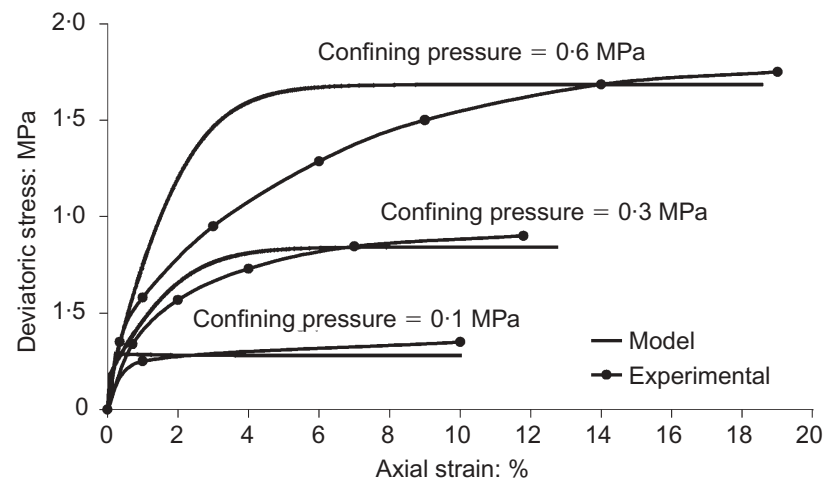

(a)

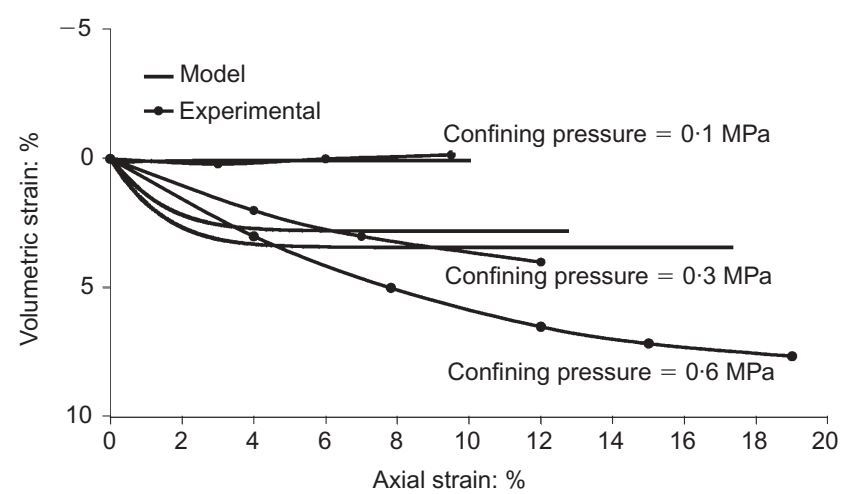

(b)

Fig. 16. Triaxial tests on foundation soil: (a) deviatoric stressvertical strain curves; (b) volumetric-axial strain curves

layer as soon as a new layer is added. In periods of no rain, a suction of $1 \mathrm{MPa}$ is imposed. This leads to evaporative fluxes, which reduces somewhat the net infiltration.

The impounding history of the reservoir is simulated by means of a set of periods in which the water level changes linearly between the two extreme times $\left(t_{\mathrm{a}}, t_{\mathrm{b}}\right)$ considered. To this end, the auxiliary function

$$
p(t)=\frac{t-t_{\mathrm{b}}}{t_{\mathrm{a}}-t_{\mathrm{b}}} \text { for } t_{\mathrm{a}}<t \leqslant t_{\mathrm{b}}
$$

is introduced. Water pressure at a point of the boundary having a vertical height $y$ above the reference level, is given by (see Fig. 19) 


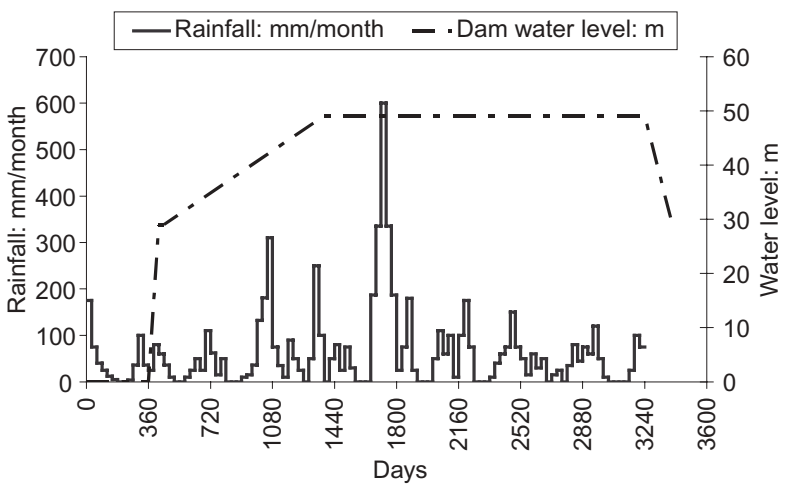

Fig. 17. Rainfall and reservoir levels considered in model calculations

$$
p_{\mathrm{w}}=\gamma_{\mathrm{w}} h(t)
$$

where

$$
\begin{aligned}
& h(t)=H \times p(t)-y \quad \text { if } H \times p(t)>y \\
& h(t)=0 \quad \text { if } H \times p(t) \leqslant y
\end{aligned}
$$

where $H$ is the maximum reservoir level in the period considered.

Normal stresses on the upstream boundary are specified equal to the liquid water pressure:

$$
\sigma_{\mathrm{n}}=p_{\mathrm{w}}
$$

Because of water level rise, the upstream rockfill shells reach full saturation. However, the rockfill model is properly described in terms of total stresses, and no consideration of effective or net stress is made. Because air pressure was assumed constant and equal to zero in modelling the dam, net and total stresses are identical under unsaturated conditions. However, when the water level rises in the upstream shell, the water pressure becomes positive, and effective stresses govern the behaviour of rockfill. In order to model this transition the net stress concept defined in the BBM model was also implemented in the present analysis for the rockfill model. In fact, CODE_BRIGHT defines net (or effective, if appropriate) mean stress as

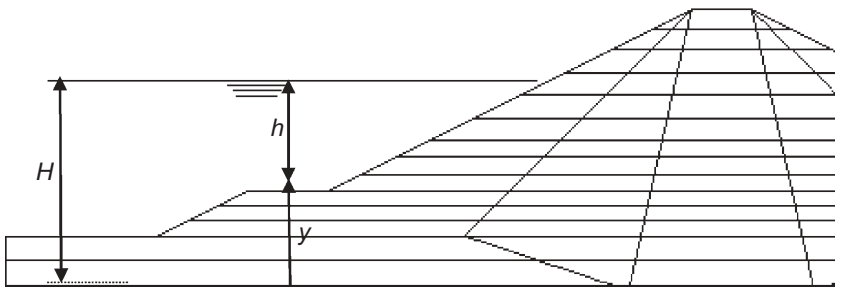

Fig. 19. Variables used to simulate impounding

$$
p=\sigma_{\text {average }}-\max \left(u_{\mathrm{w}}, u_{\mathrm{a}}\right)
$$

where $\sigma_{\text {average }}$ is the mean total stress, and $u_{\mathrm{w}}, u_{\mathrm{a}}$ are the water and air pressures respectively.

Construction and impounding was idealised in several stages, defined below, which follow the stages defined in Naylor et al. (1997). The initial time adopted in the simulation performed, $t=0$, corresponds to the beginning of dam construction.

[A] Construction to elevation $29 \mathrm{~m}$ $t=0-180$ days

[B] Construction to elevation $47 \mathrm{~m}$ $t=180-360$ days

[C] Impounding of the reservoir to elevation $29 \mathrm{~m}$ $t=360-420$ days

[D] Completion of construction to elevation $55 \mathrm{~m}$ $t=420-450$ days

[E] Impounding of reservoir to elevation $49 \mathrm{~m}$ $t=450-1500$ days

[F] Water level maintained in reservoir at elevation $49 \mathrm{~m}$ $t=1500-3240$ days

[G] Water level decreased in reservoir to level $20 \mathrm{~m}$ $t=3240-3600$ days

A relatively high initial suction, $s=20 \mathrm{MPa}$, was assumed at the time of rockfill placement. It corresponds to a relative humidity of $85 \%$. This assumption reflects an aerated condition of the pervious rockfill. However, a lower suction, $s=$ $0.5 \mathrm{MPa}$, was assumed for as-compacted conditions of the clay core, as mentioned before.

In relatively weak rockfill made of schists and greywackes, yielding starts at very low stresses, owing to the

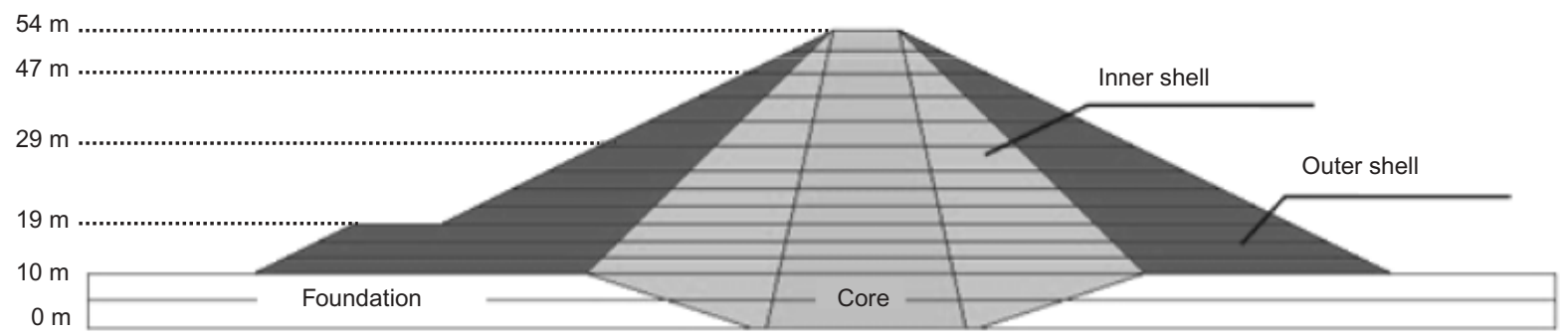

(a)

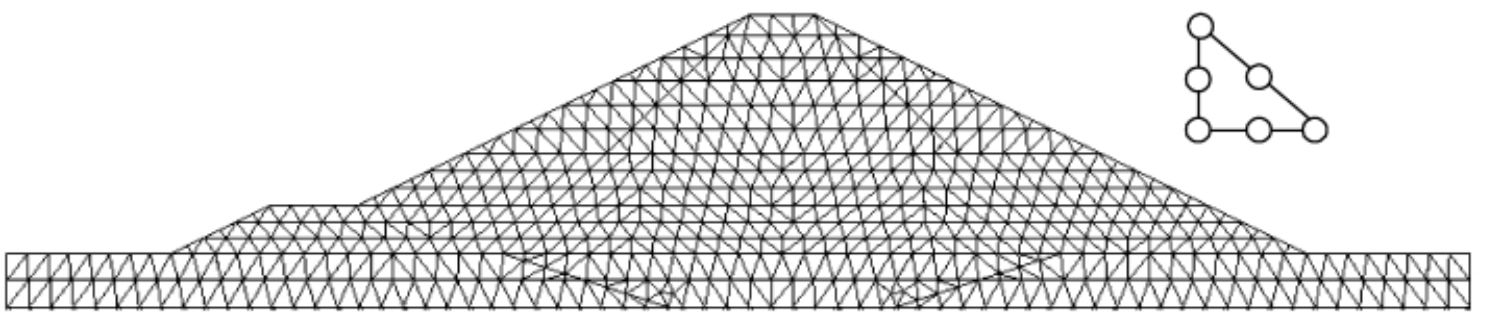

(b)

Fig. 18. (a) Geometry of dam for model calculations; (b) discretised model using quadratic triangles 
onset of particle breakage, and therefore quite a low initial yield stress was assumed for the inner and outer rockfill shells.

\section{BASE CASE}

A base case was defined on the basis of the material parameters derived from the laboratory tests performed (Tables 2, 3 and 4). The evolution of calculated vertical displacements with depth at the position of extensometers I1, I3 and I6 is shown in Fig. 20 for stages [A] to [E], defined above. The agreement is good for the extensometer centred on the clay core. Calculated displacements are underestimated for extensometers I1 and I6, located essentially within the upstream and downstream inner rockfill shells. The complete evolution in time of vertical and horizontal displacements at marker points M54, J54 and J40 is given in Fig. 21. M54 and J54 are located at the upstream and downstream limits of the clay core, whereas J40 is a point above mid-height in the downstream shoulder. The best agreement is found for the vertical settlements measured at J54.

The model is able to follow the increasing rate of settlement associated with intense rainfall periods at times $t=$ 1080 days and $t=1800$ days (see Fig. 17). Relatively high settlement rates are also associated with rainfall events immediately after construction, and this is also a feature of the model. Relatively high rainfall intensities at other intermediate times ( $t=1350$ days) do not seem to increase the settlement rate in reality, as well as in the model. The explanation for this behaviour is provided in Fig. 21, where the calculated evolution of water pressures in a point of the lower third of the inner rockfill of the downstream shoulder is also indicated. The settlement rate increases rapidly whenever suction reaches a lower value than all the previously calculated pressures. This is not the case for the rainfall at $t$ $=1350$ days or at $t>1800$ days. This behaviour is a direct consequence of model formulation, and it will be examined further when the calculated stress paths are discussed.

Horizontal displacements also seem to be affected by extreme rainfall events, but in a less clear manner. Calculated base values are reasonably accurate for markers M54 and J40. Measured horizontal displacements at marker J54 look abnormally high.

Also reflected in the model calculations is the effect of the partial water level drawdown at the end of the simulated period (Stage $[\mathrm{G}]$ ). Because of the effective stress increase in the upstream shells, some settlements are recorded, as well as a decrease in horizontal displacements. The calculated response follows the elastic behaviour defined for the base case and is, in general, less marked than actual measurements.

The calculated stress transfer phenomenon between shells and core is observed in Fig. 22, where vertical and horizontal stresses along a horizontal line, $13 \mathrm{~m}$ above the bottom of the clay core, are represented. Vertical stresses at the interface between the inner shell and outer shell (upstream) reflect the significant collapse calculated for the upstream inner shell at stage [D] as a result of the first partial impoundment of the reservoir. Similar interactions are observed between the inner shell and the deformable core. The initial symmetric distribution of stresses becomes nonsymmetric as a result of the collapse deformations experienced by the upstream shells and clay core.

Stress cells oriented in different directions provided information on the mean and deviatoric stresses $\left(q=\sqrt{3 J_{2 \mathrm{D}}}\right)$ on two horizontal sections (at 10 and $19 \mathrm{~m}$ ) in the clay core and adjacent shell. They are reproduced in Fig. 23, together with the calculated values. Mean values are reasonably well reproduced, but the large deviatoric stresses reported for the rockfill shells are not matched by calculations.

Flow and deformation processes taking place within the dam can be followed if some key variables, such as liquid pressure, degree of saturation and irreversible volumetric strains, are plotted. This is shown in Fig. 24, for points located in a horizontal plane located at elevation $10 \mathrm{~m}$. Points in the upstream shell become soon saturated, and they follow the water pressure marked by the reservoir level. In contrast, the downstream shell maintains a low degree of saturation, and its suction is essentially controlled by the weather action. Calculated suctions, very high at the time of construction, remain later in the range $0-0.7 \mathrm{MPa}$, in response to rainfall and evaporation effects. These fluctuations also affect the clay core, although in a more damped manner. Fig. 24(c) points out that irreversible volumetric strain is induced only at some instants, where particularly low values of suction exist. Those instants correspond to the recorded acceleration of settlement rates mentioned before.

The dam behaviour is further illustrated in Figs 25(b) and 25(d), where the mean net stress-suction paths of some points located at elevation $10 \mathrm{~m}$ are given. The first part of the path is essentially common to all the points considered: it reflects the increase in mean stress associated with construction. Impoundment of the upstream shells results in a rapid decrease of suction at a relatively constant mean stress. Points within the downstream shell never become saturated.

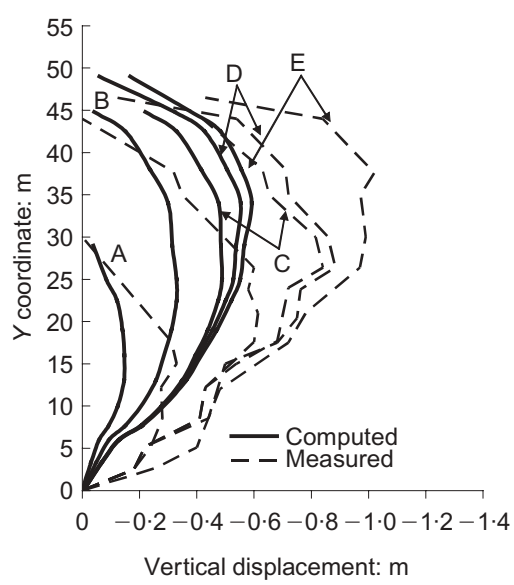

(a)

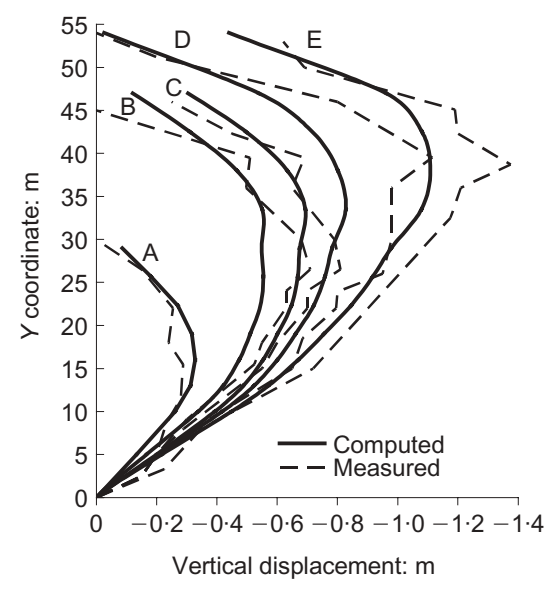

(b)

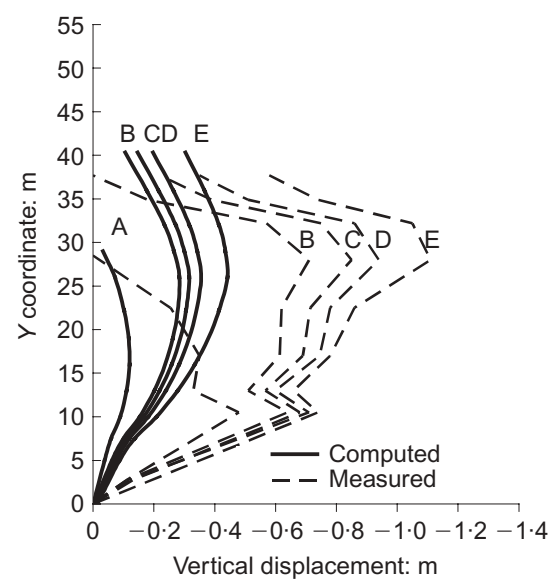

(c)

Fig. 20. Calculated and measured vertical displacements at position of extensometers (a) I1, (b) I3 and (c) I6 during construction and impoundment for stages [A] to [E]: base case. Elevation 0 corresponds to bottom of clay core 

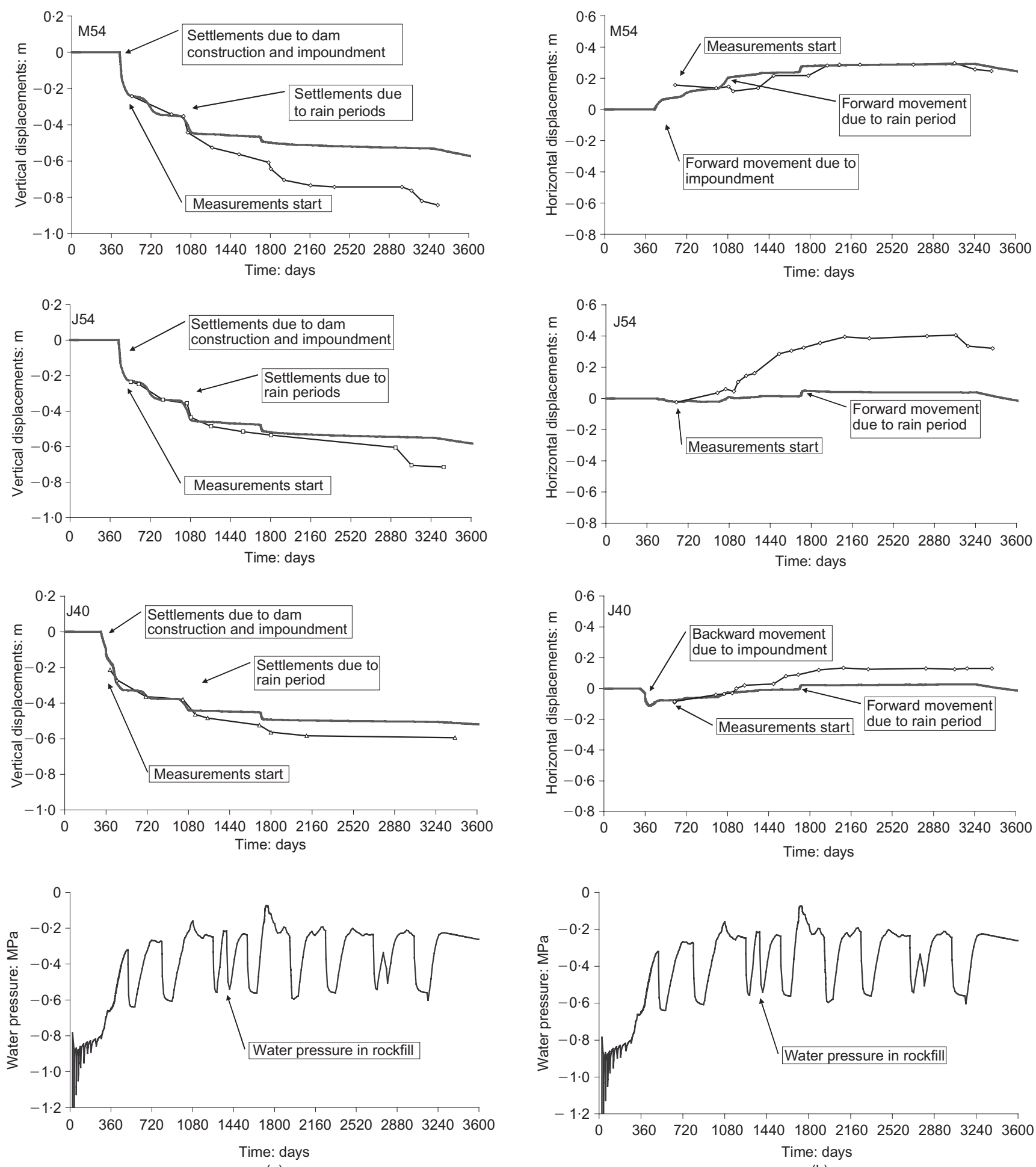

(a)

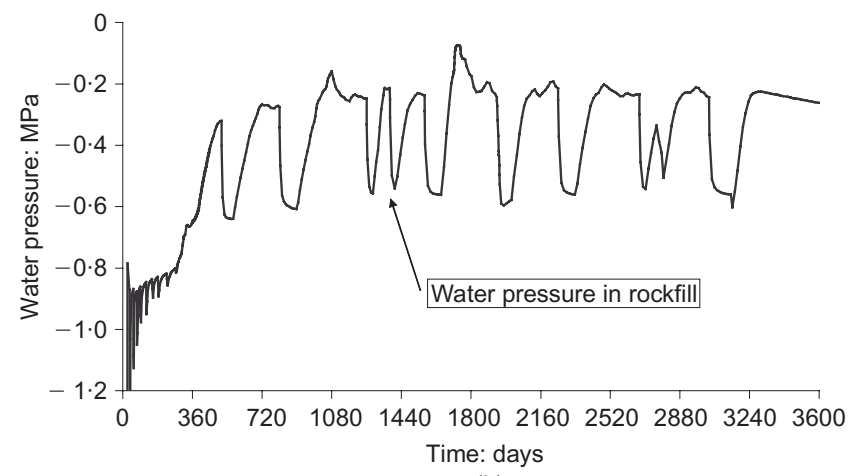

(b)

Fig. 21. Evolution of (a) vertical and (b) horizontal displacements of surface markers M54, J54 and J40: comparison of measured and calculated values for base case. Also shown is calculated water pressure (suction) at a reference point within inner downstream rockfill

Instead, they experience wetting-drying cycles. Suction cycles are also calculated in the downstream part of the core. For most of the time, cycles are within the elastic zone defined for the constitutive model. However, an extreme rainfall may displace the current yield locus, thus inducing an irreversible volumetric strain. Only rainfall events that are capable of decreasing the suction to lower values than the worst case in previous history are capable of inducing further irreversible strains. The shape and position of yield loci for the inner downstream rockfill and the core at two times during construction and impoundment (collapse is being induced) are shown in Figs 25(b) and 25(d) to illustrate this effect. The calculated changes in porosity are shown in Figs 25(a) and 25(c) for points in the clay core and shells. Note that the decrease in porosity for comparable points of the upstream and downstream inner shells is similar, although the wetting history is rather different. The final decrease in porosity of the upstream shell due to the reduction of the water level in the reservoir is also shown in the figure. The model indicates that the upstream part of the 


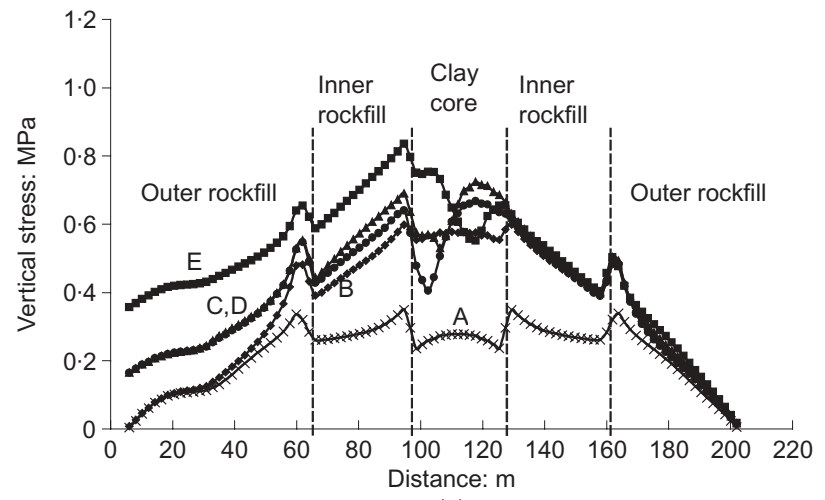

(a)

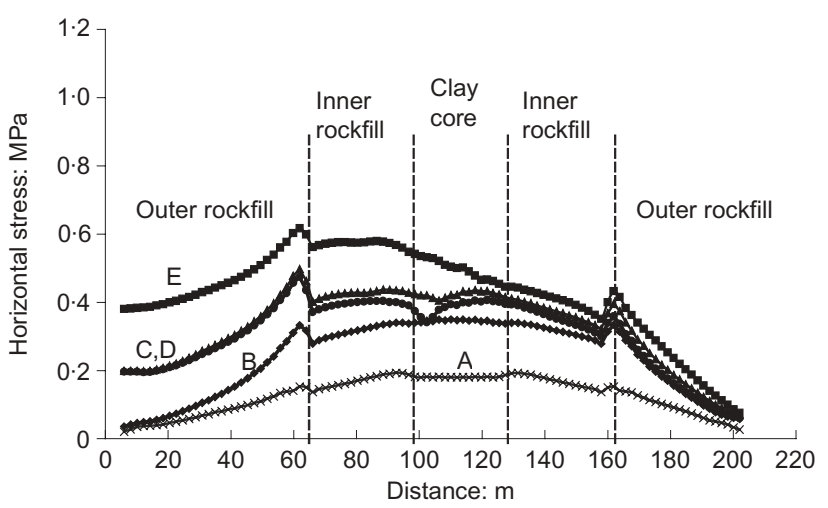

(b)

Fig. 22. (a) Vertical and (b) horizontal stresses during construction and impoundment (Stages $[A]$ to $[E]$ ) on a horizontal plane at elevation $13 \mathrm{~m}$ above bottom boundary of clay core

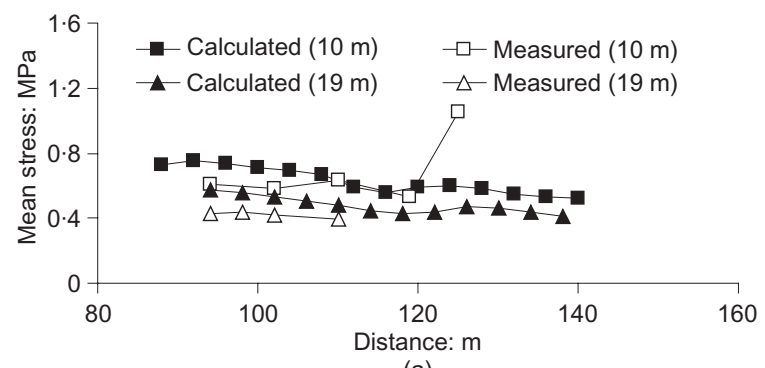

(a)

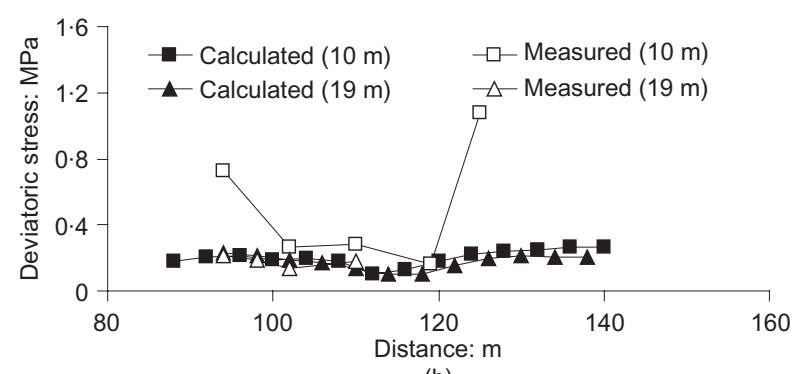

(b)

Fig. 23. Calculated and measured (a) mean and (b) deviatoric stress at the end of impoundment (Stage [E]) for elevations $10 \mathrm{~m}$ and $19 \mathrm{~m}$ : base case

clay core becomes saturated after impoundment. Mean net stresses become effective mean stresses, and subsequent changes in reservoir elevation are reflected in changes in mean effective stress (at zero suction). The drawdown imposed at the end of the simulation period considered is reflected by an increase in the effective stress of points

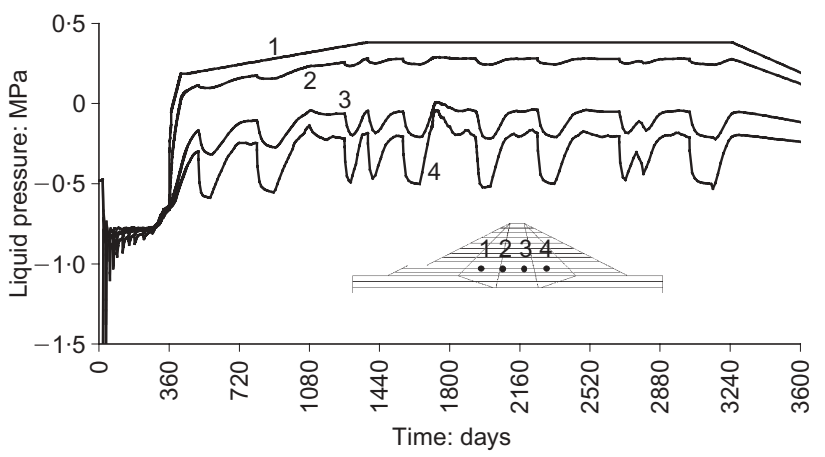

(a)

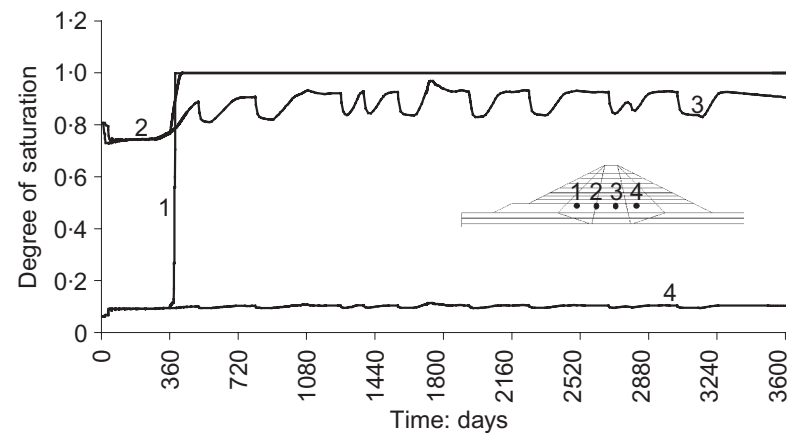

(b)

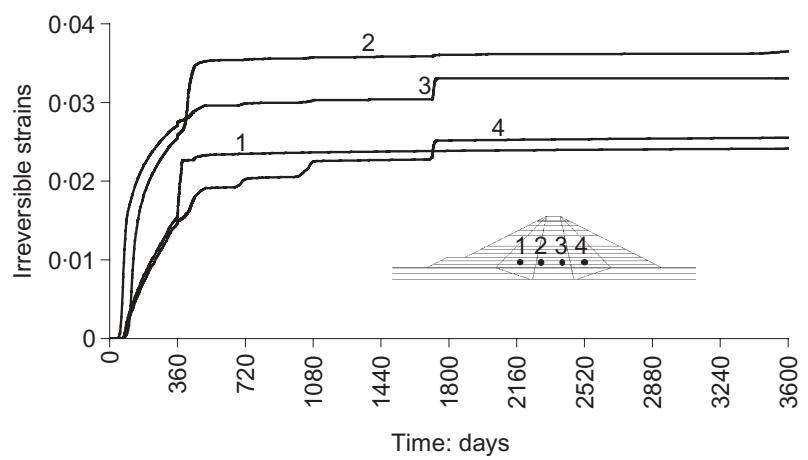

(c)

Fig. 24. (a) Calculated liquid pressure, (b) degree of saturation and (c) irreversible volumetric strains for points indicated: base case

located within the upstream shells and core (Figs 25(b), 25(d)).

\section{SCALE AND PERMEABILITY EFFECTS}

The reference case, based on laboratory test results, provides a model response, which is satisfactory in general terms. Discrepancies remain, however: measured settlements of upstream and downstream shells tend to be higher than calculated values; computed stresses are more uniform than measured values, especially the deviatoric ones; and measured horizontal displacements at some locations are substantially higher than model calculations.

Several reasons may be proposed to explain some discrepancies. The validity of scaled compacted samples is probably a key issue. Marachi et al. (1969) found that scaled grain-size distributions lead to comparable strength envelopes. However, one should expect an increased compressibility when the size of particles increases, owing to the size effects of crack propagation in brittle materials. It is also clear that a few compacted laboratory specimens are hardly representative of a large-scale structure such as a dam.

There are other reasons for discrepancies, which may be hidden at first sight. An important one refers to the effect of 


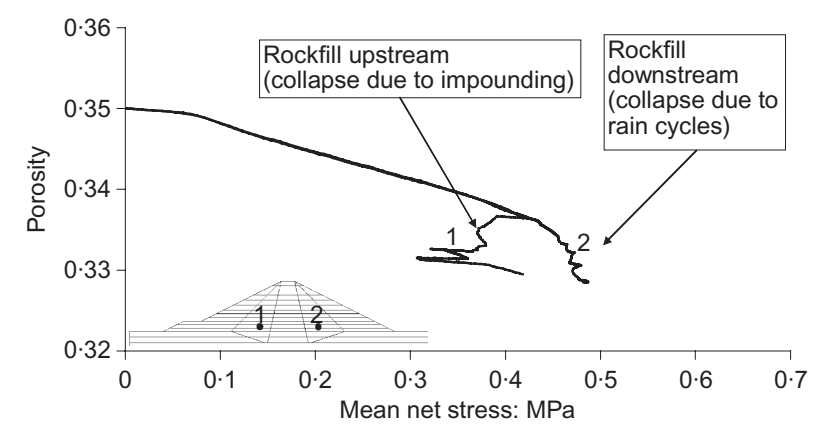

(a)

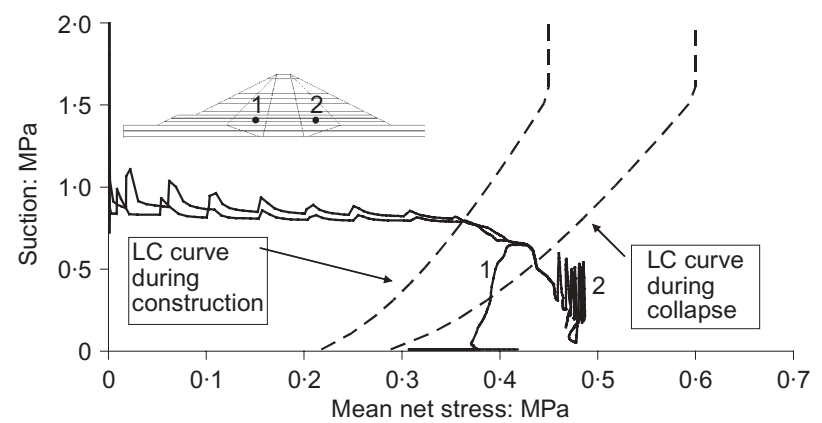

(b)

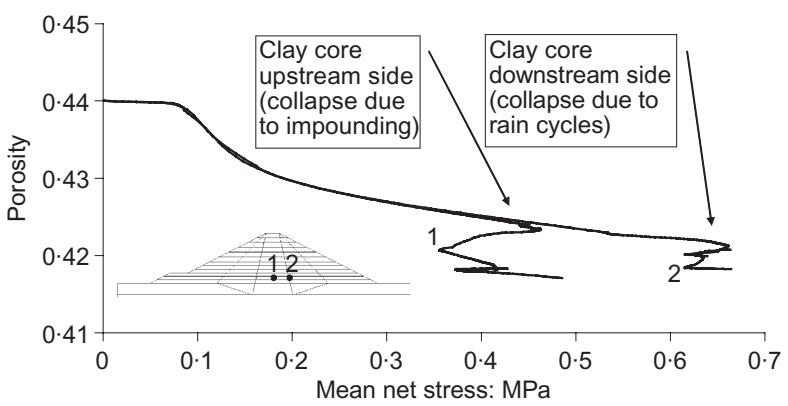

(c)

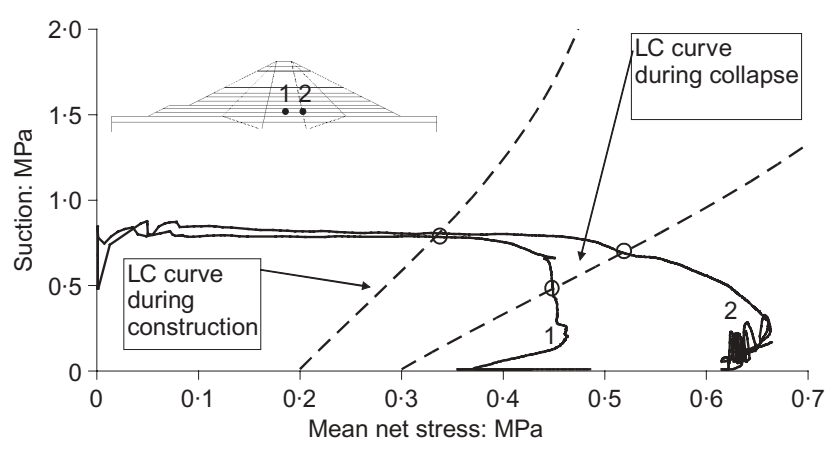

(d)

Fig. 25. Stress-liquid pressure and stress-porosity plots for points indicated of $(a, b)$ inner rockfill and $(c, d)$ clay core: base case

permeability and, more generally, to hydraulic properties. Rockfill permeability was inferred from available grain size distribution curves. The actual field value is, however, uncertain.

There was an interest in exploring the effect of changing some of these material properties on the computed response of the dam. A change in rockfill permeability implies a change in the suction field for a given rainfall/evaporation regime. An increase in permeability results in lower water potential gradients and a more limited reduction of initial suction. Therefore a reduction of rockfill collapse should be expected in this case. Fig. 26 shows the effect of a tenfold increase in the rockfill permeability (for both inner and outer shells) on the vertical settlements of marks M54, J54 and $\mathrm{J} 40$ and the evolution of representative suctions. Suctions are now higher, and a reduction of vertical displacements is computed. Heavier rains will be required in this case to develop the full collapse potential of the rockfill.
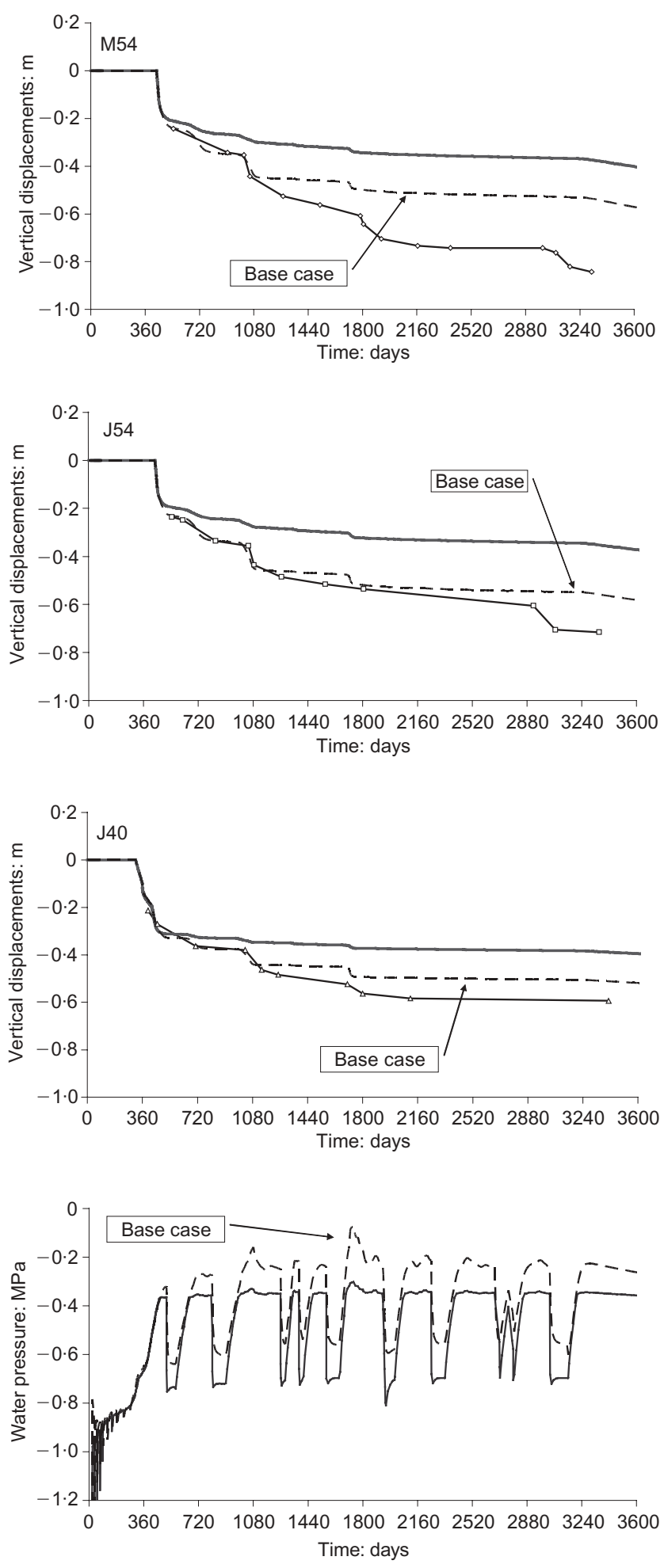

Fig. 26. Evolution of vertical displacements of surface markers M54, J54 and J40: comparison of measured and calculated values when the rockfill permeability of shells is increased 10 times with respect to base case. Also indicated is the calculated evolution of water pressure (suction) at a reference point within inner downstream rockfill 
The effect of particle size on rockfill compressibility was recently investigated by Montobbio (2002). Suction control oedometer tests were performed on specimens of crushed quartzitic shale of scaled grain-size distribution (cumulative distribution curves were kept parallel). The test results were interpreted through the elastoplastic compressibility model described by Oldecop \& Alonso (2001). Fig. 27 shows the measured values of the saturated virgin compressibility index $\lambda_{0}^{\mathrm{d}}$ plotted in terms of the $D_{50}$ value of the grain size distribution. Coarser specimens are more deformable, and $\lambda_{0}^{\mathrm{d}}$ increases linearly with $\log D_{50}$. Naylor et al. (1986) reported the gradation curves of rockfill in situ and the curves used in different testing devices. For the $500 \mathrm{~mm}$ diameter oedometer, a value of $D_{50}=18 \mathrm{~mm}$ was found. In situ material is characterised by $D_{50}=100 \mathrm{~mm}$. For these two values, Fig. 27 suggests that the compressibility index of the in situ rockfill may be $50 \%$ higher than the laboratory-determined value. The results of increasing the elastoplastic compressibility index $\left(\lambda^{\mathrm{i}}+\lambda_{0}^{\mathrm{i}}\right)$ of the rockfill shells by $50 \%$ with respect to the base case are shown in Figs 28 and 29. A significant improvement of the calculated settlements is now found. The measured downstream settlements (I6) remain higher than the model calculations, and this suggests that a more compressible material than expected was placed in situ. The evolution in time of vertical displacements is plotted in Fig. 29. Water pressure in the rockfill does not change, because changes in porosity have a negligible effect on rockfill permeability. Model calculations are now closer to measured surface settlements. Actual settlements indicate

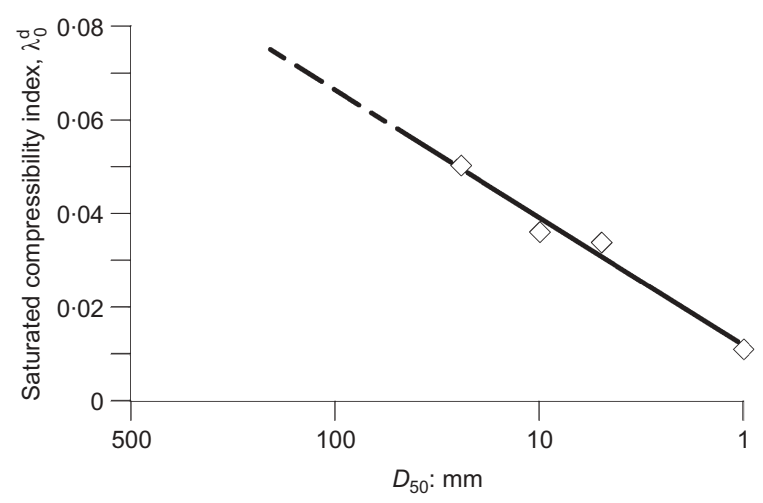

Fig. 27. Variation of virgin saturated compressibility index of scaled gravel specimens of quartzitic shale with grain size distribution (Montobbio, 2002) a more marked creep deformation than the effect provided by the creep coefficients initially selected. However, within the time interval used to make the comparisons (10 years), creep effects are of minor significance if compared with suction-induced phenomena.

\section{CONCLUSIONS}

Recent developments in rockfill constitutive behaviour provide new tools for the coupled flow and deformation analysis of rockfill embankments, which offer definite advantages over previously reported modelling approaches. Zoned earth dams integrate fine compacted soils in the impervious core and rockfill shoulders into a single structure. In both types of material the role of suction or, alternatively, the prevailing relative humidity is a fundamental variable to explain the behaviour of the dam during construction, impounding and operation.

Numerical models developed within the framework of effective stress analysis require some ad hoc computational devices to handle the development of strains as a consequence of suction or relative humidity changes, both in the core and in the rockfill shoulders. They may be useful to reproduce stress and deformation states at a given stage of dam construction and operation, even if the representation of material behaviour is inconsistent with physical phenomena. However, they lack the possibility of handling environmental factors, such as a weather regime. The Beliche Dam case highlighted the relevant effects of climate, which are directly responsible for the behaviour of the downstream shoulder.

Ideally, the constitutive models used require suctioncontrolled testing for the determination of material parameters. It has been shown, however, that the performance of two series of oedometer and triaxial tests under dry and saturated conditions allows the identification of model parameters. Despite the limitations of a methodology for parameter determination that relies on a limited number of tests on compacted specimens, the computed dam response for the set of parameters derived in this manner proved to be quite satisfactory. It has been argued that size effects tend to reduce the compressibility of coarse materials as determined in laboratory experiments. A corrected compressibility, which incorporates this effect, is better able to reproduce the field data.

One of the main advantages of the proposed modelling approach is the consistent integration of water transfer and deformation mechanisms. It has been shown that the defor-

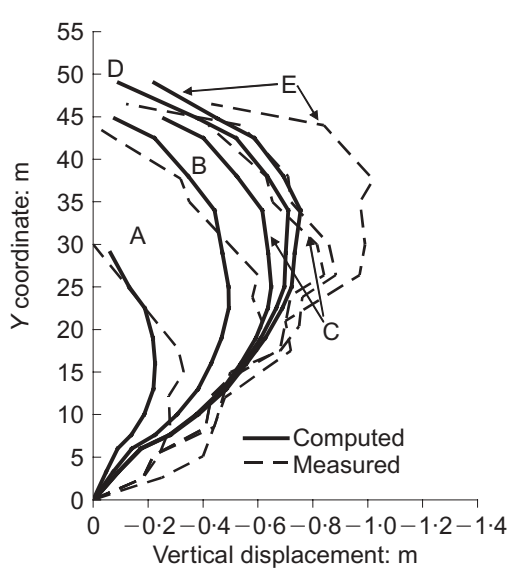

(a)

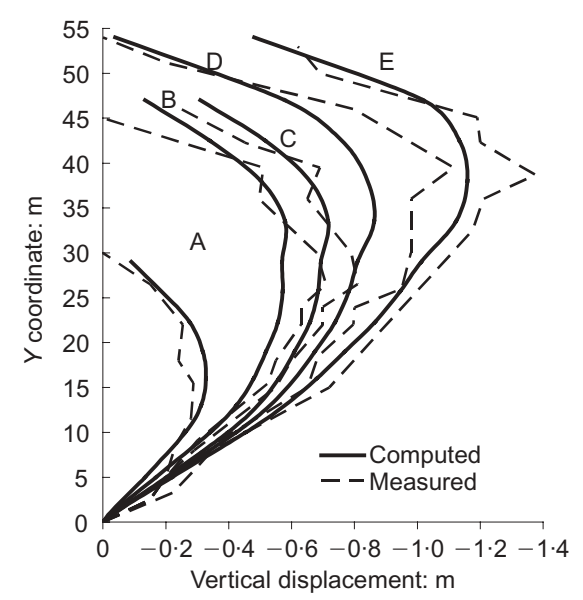

(b)

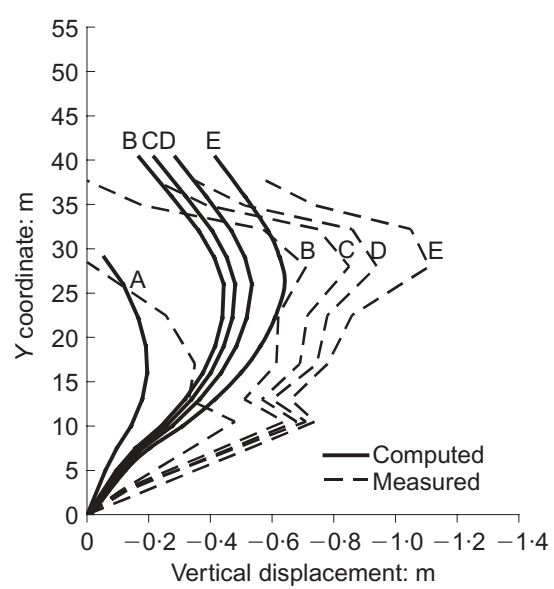

(c)

Fig. 28. Calculated and measured vertical displacements at position of extensometers (a) I1, (b) I3 and (c) I6 during construction and impoundment for stages $[\mathrm{A}]$ to $[\mathrm{E}]$. Elevation 0 corresponds to bottom of clay core. Virgin compressibility index of rockfill increased by $50 \%$ 

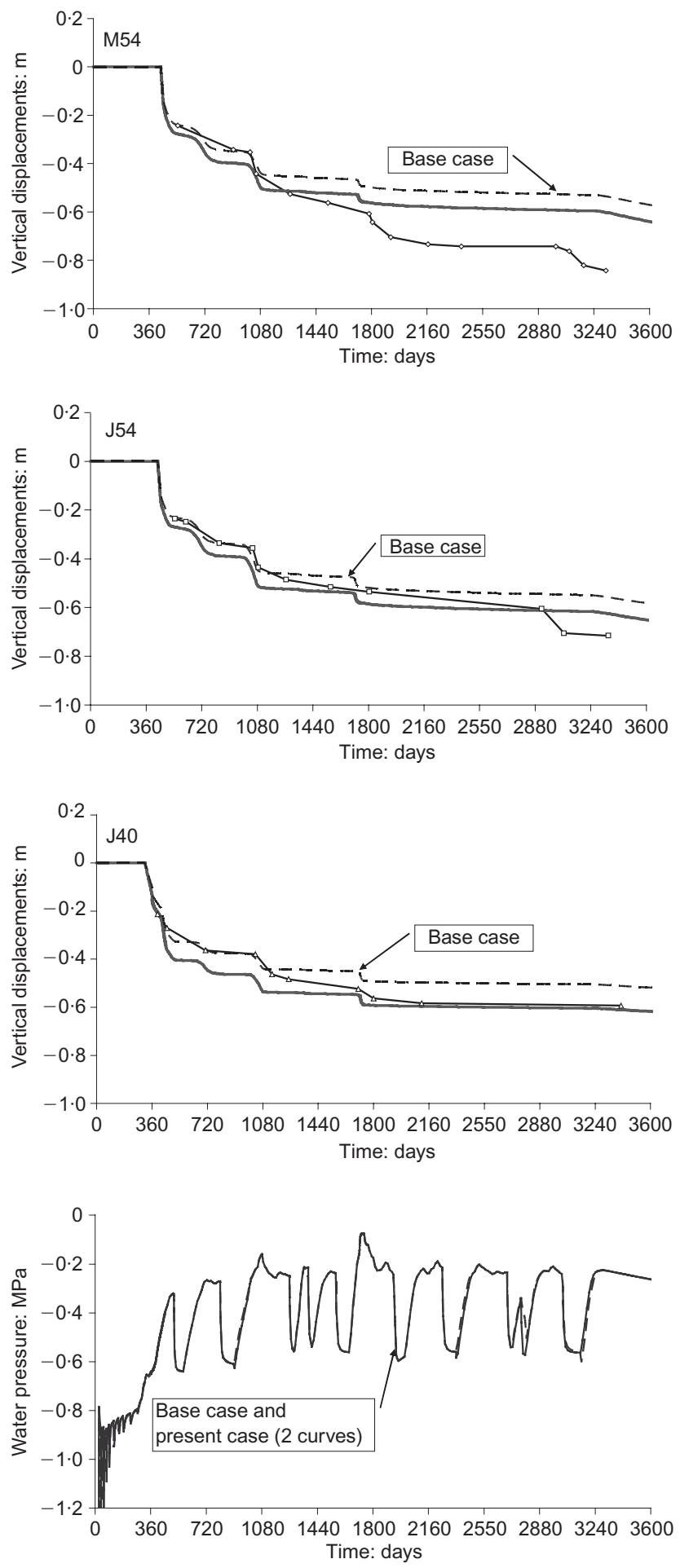

Fig. 29. Evolution of vertical displacements of surface markers M54, J54 and J40. Comparison of measured and calculated values when the rockfill virgin compressibility index is increased $50 \%$ with respect to the base case. Also indicated is the calculated evolution of water pressure (suction) in a reference point within the inner downstream rockfill

mations of the dam, immediately after construction, are highly dependent on the weather regime. The analysis helps to distinguish deformations associated with suction changes from pure creep effects. The former may be relevant for a number of years following dam completion. In fact, it is the joint consideration of the rainfall pattern and the rockfill permeability that dictates the time period in which 'waterrelated effects' may deform the structure in time. These effects, which have been associated with the breakage of particles, tend to vanish when the rockfill reaches, for the first time, a $100 \%$ relative humidity. Flooding of the rockfill is not necessary to reach this condition. At later stages, pure creep effects are held responsible for rockfill deformation.

\section{ACKNOWLEDGEMENTS}

The authors would like to acknowledge and express their thanks for the careful review of the original manuscript made by Professor Maranha das Neves from the Instituto Superior Técnico of Lisbon.

\section{NOTATION}

(RM refers to Rockfill Model and BBM to the Barcelona Basic Model for unsaturated soil.)

$a$ fraction of volumetric creep coefficient that provides deviatoric creep coefficient (RM)

D matrix of elastic coefficients

$E$ elastic modulus

$e$ void ratio

$e_{0}$ initial void ratio

$F$ yield function (RM and BBM)

$F_{0}$ reference stress to normalise $F$ (RM and BBM)

$G$ plastic or viscoplastic potential (RM and BBM)

$g$ gravity

I identity matrix

$J_{1} \quad$ first invariant of stress tensor $\left(=\sigma_{1}+\sigma_{2}+\sigma_{3}\right)$

$J_{2 \mathrm{D}}$ second invariant of deviatoric stress tensor, $\left(=\frac{1}{6}\left[\left(\sigma_{1}-\sigma_{2}\right)^{2}+\left(\sigma_{1}-\sigma_{3}\right)^{2}+\left(\sigma_{2}-\sigma_{3}\right)^{2}\right]\right.$

$$
\left.+\sigma_{12}^{2}+\sigma_{13}^{2}+\sigma_{23}^{2}\right)
$$

$K$ hydraulic conductivity

$K_{\mathrm{r}}$ relative permeability

$k$ intrinsic permeability

$k_{\mathrm{s}}$ parameter describing increase in cohesion with suction (RM and BBM)

$M$ slope of critical-state line (RM and BBM)

$M_{\text {dry }}$ slope of critical-state line of rockfill material for a very dry state $(\mathrm{RM})$

$M_{\text {wet }}$ slope of critical-state line of rockfill material for a saturated state (RM)

$p$ mean total stress (RM); mean net stress (BBM)

$p_{\text {atm }}$ atmospheric pressure

$p^{\mathrm{c}}$ reference stress $(\mathrm{BBM})$

$p_{\mathrm{s}}$ apparent yield stress in tension (RM and BBM)

$p_{\mathrm{y}} \quad$ threshold yield mean stress for onset of clastic phenomena of rockfill material (RM)

$p_{\mathrm{w}} \quad$ water pressure

$p_{0}$ preconsolidation stress (RM and $\left.\mathrm{BBM}\right)$

$p_{0}^{*} \quad$ yield stress for a very dry rockfill (RM); preconsolidation stress for saturated conditions (BBM)

$q$ deviatoric stress $\left(=\sigma_{1}-\sigma_{3}\right)$

$r$ parameter defining maximum soil stiffness (BBM)

$S_{\mathrm{r}}$ degree of saturation

$S$ suction

$s_{0}$ initial suction

$u_{\mathrm{a}}, u_{\mathrm{w}}$ air and water pressures

$\alpha$ parameter defining non-associativeness of plastic potential (RM and BBM)

$\alpha_{\mathrm{s}}$ parameter describing rate of change of compressibility with total suction (RM)

$\beta$ parameter controlling rate of increase of soil stiffness with suction (BBM)

$\beta^{\mathrm{c}}$ parameter describing effect of suction on viscosity coefficient for volumetric creep (RM)

$\Gamma \quad$ fluidity parameter (RM)

$\boldsymbol{\varepsilon}, \boldsymbol{\varepsilon}^{\mathrm{e}}, \boldsymbol{\varepsilon}^{\mathrm{p}}, \boldsymbol{\varepsilon}^{\mathrm{vp}}$ total, elastic, plastic and viscoplastic strain tensors respectively

$\varepsilon_{\mathrm{d}}$ deviatoric strain (RM)

$\varepsilon_{\mathrm{V}} \quad$ volumetric strain (RM and BBM)

$\varepsilon_{\mathrm{v}}^{\mathrm{d}} \quad$ volumetric strain component associated with clastic deformation mechanism (RM) 
$\varepsilon_{\mathrm{v}}^{1} \quad$ volumetric strain component associated with particles rearrangement (RM)

$\dot{\varepsilon}$ strain rate tensor

$\eta_{\mathrm{d}} \quad$ deviatoric viscosity coefficient (RM)

$\eta_{\mathrm{v}}$ volumetric viscosity coefficient (RM)

$\kappa$ elastic stiffness coefficient for changes in mean stress (RM and BBM)

$\kappa_{\mathrm{S}} \quad$ Elastic stiffness coefficient for changes in suction (RM and BBM)

$\Lambda$ plastic multiplier (RM)

$\lambda$ virgin compressibility (BBM)

$\lambda(0)$ virgin compressibility for saturated conditions (BBM)

$\lambda^{\mathrm{d}} \quad$ compressibility parameter for virgin states associated with clastic deformation mechanism (RM)

$\lambda_{0}^{\mathrm{d}} \quad$ virgin clastic compressibility for saturated conditions (RM)

$\lambda^{\mathrm{i}}$ compressibility parameter for virgin states associated with particle rearrangement (RM)

$\lambda^{t}$ creep coefficient (RM)

$\mu$ volumetric creep parameter for saturated conditions (RM)

$\mu_{\mathrm{W}} \quad$ viscosity of fluid (water)

$v$ Poisson's ratio

$\rho_{\mathrm{w}}$ density of fluid (water)

$\sigma_{\mathrm{v}} \quad$ vertical confining stress

$\sigma_{1}, \sigma_{2}, \sigma_{3}$ total principal stresses

$\phi(F)$ flow function (RM)

\section{REFERENCES}

Alonso, E. E. (2003). Exploring the limits of unsaturated soil mechanics: the behaviour of coarse granular soil and rockfill. 11th Spencer J. Buchanan Lecture. College Station: Texas A\&M University. (http://ceprofs.tamu.edu/briaud/buchanan.htm).

Alonso, E. E. \& Batlle, F. (1995). Construction and impoundment of an earthdam. In Modern issues in non-saturated soils (eds A. Gens, P. Jouanna and B. A. Schrefler), pp. 357-396. Vienna: Springer-Verlag.

Alonso, E. E., Batlle, F., Gens, A. \& Lloret, A. (1988). Consolidation analysis of partially saturated soils: application to earthdam construction. Proceedings of the international conference on numerical methods in geomechanics, Innsbruck, Vol. 2, pp. $1303-1308$.

Alonso, E. E., Gens, A. \& Josa, A. (1990). A constitutive model for partially saturated soil. Géotechnique 40, No. 3, 405-430.

Azevedo Filho, R. N. (1990). Análise do comportamento de barragens pelo método dos elementos finitos utilizando un método elasto-plástico. Masters thesis, Pontificia Universidade Católica, Rio de Janeiro.

Chávez, C. \& Alonso, E. E. (2003). A constitutive model for crushed granular aggregates which includes suction effects. Soils Found. 43, No. 4, 215-227.

Costa, L. M. da (2000). Análise hidro-mecánica de solos nao saturados com aplicaçao a barragem de terra. Doctoral thesis, COPPE/UFRJ, Rio de Janeiro.

DIT-UPC (2002). CODE_BRIGHT, a 3-D program for thermohydro-mechanical analysis in geological media: User's guide. Barcelona: Centro Internacional de Métodos Numéricos en Ingeniería (CIMNE).

Farias, M. M. (1993). Numerical analysis of clay core dams. PhD thesis, University College of Swansea.

Gens, A., Alonso, E. E., Suriol, J. \& Lloret, A. (1995). Effect of structure on the volumetric behaviour of compacted soil. Proc. 1st Int. Conf. on Unsaturated Soils, Barcelona 1, 83-88.

Justo, J. L. \& Durand, P. (2000). Settlement-time behaviour of granular embankments. Int. J. Numer. Anal. Methods Geomech. 4, No. 3, 281-303.

Justo, J. L. \& Saura, J. (1983). Three-dimensional analysis of Infiernillo dam during construction and filling of the reservoir. Int. J. Numer. Anal. Methods Geomech. 7, No. 2, 225-243.

Kogho, Y. (2003). Review of constitutive models for unsaturated soils. Proc. 2nd Asian Conf. on Unsaturated Soils, Osaka, 21-40.

Marachi, N. D., Chan, C. K., Seed, H. B. \& Duncan, J. M. (1969).
Strength and deformation characteristics of rockfill materials, Report No. TE-69-5. University of California: Department of Civil Engineering.

Maranha, J. R. (1997). Analysis of embankment dams: computational aspects. $\mathrm{PhD}$ thesis, University College of Swansea.

Maranha das Neves, E. (2002). Some considerations about rockfill mechanics: Pacheco Silva Lecture. Soils and Rocks 25, No. 3, $161-203$.

Marsal, R. J., Arellano, L. R., Guzmán, M. A. \& Adame, H. (1976). El Infernillo: Behaviour of dams built in Mexico. Instituto de Ingeniería, UNAM, Mexico.

Mateus da Silva, J. M. M. (1996). Modelaçao de colapso e da fluência em aterros. Doctoral thesis, Faculdade de Engenharia da Universidade do Porto.

Montobbio, D. (2002). Estudio de la granulometría en la compresibilidad de escolleras. Final diploma thesis. ETS de Ingenieros de Caminos, UPC, Barcelona.

Mualem, Y. (1976). A new model for predicting the hydraulic conductivity of unsaturated porous media. Water Resour. Res. 12, No. 3, 513-522.

Naylor, D. J., Maranha das Neves, E., Mattar, D. Jr \& Veiga Pinto, A. A. (1986). Prediction of construction performance of Beliche Dam. Géotechnique 36, No. 3, 359-376.

Naylor, D. J., Maranha das Neves, E. \& Veiga Pinto, A. A. (1997). A back-analysis of Beliche Dam. Géotechnique 47, No. 2, $221-$ 233.

Naylor, D. J., Tong, S. L. \& Shahkarami, A. A. (1989). Numerical modelling of saturation shrinkage. Proc. 3rd Int. Symp. on Numerical Models in Geomechanics, Niagara Falls, 636-648.

Nobari, E. \& Duncan, J. (1972). Effect of reservoir filling on stresses and movements in earth and rockfill dams, Report No. TE-72-1, pp. 1-186. Berkeley: Office of Research Services, University of California.

Oldecop, L. \& Alonso, E. E. (2001). A model for rockfill compressibility. Géotechnique 51, No. 2, 127-139.

Oldecop, L. \& Alonso, E. E. (2002). Fundamentals of rockfill timedependent behaviour. Proc. 3rd Int. Conf. on Unsaturated Soils, Recife 2, 793-798.

Oldecop, L. \& Alonso, E. E. (2003). Suction effects on rockfill compressibility. Géotechnique 53, No. 2, 289-292.

Olivella, S., Carrera, J., Gens, A. \& Alonso, E. E. (1994). Nonisothermal multiphase flow of brine and gas through saline media. Transp. Porous Media 15, No. 3, 271-293.

Olivella, S., Gens, A., Carrera, J. \& Alonso, E. E. (1996). Numerical formulation for simulator (CODE_BRIGHT) for coupled analysis of saline media. Engng Comput. 13, No. 7, 87-112.

Pagano, L. (1996). Analisi del comportamento statico di dighe in terra zonate. Doctoral thesis, Universita'di Napoli 'Federico II'.

Perzyna, P. (1966). Fundamental problems in viscoplasticity. In Advances in applied mechanics, Vol. 9, pp. 244-368. New York: Academic Press.

Potts, D. M. \& Zdravkovic, L. (2001). Finite element analysis in geotechnical engineering: Application. London: Thomas Telford.

Sherard, J. L. \& Cooke, B. (1987). Concrete-face rockfill dam. I: Assessment. J. Geotech. Engng, ASCE 113, No. 10, 1096-1112.

Soriano, A. \& Sánchez, F. J. (1999). Settlements of railroad high embankments. Proc. 12th Eur. Conf. Soil Mech. Geotech. Eng., Amsterdam 3, 1885-1890.

Soriano, A., Sánchez, F. J. \& Serrano, C. (1990). Simulation of wetting deformations of rockfills. Proc. 2nd Eur. Conf. on Numer. Methods in Geotech. Engng, Santander, 495-517.

Sowers, G. F., Williams, R. C. \& Wallace, T. S. (1965). Compressibility of broken rock and settlement of rockfills. Proc. 6th Int. Conf. Soil Mech. Found. Engng, Montreal 2, 561-565.

Suriol, J., Gens, A. \& Alonso, E. E. (2002). Volumetric behaviour of a compacted soil upon wetting. Proc. 3rd Int. Conf. on Unsaturated Soils, Recife 2, 619-623.

Veiga Pinto, A. A. (1983). Previsao do comportamento estrutural de barragens de aterro. Thesis, LNEC, Lisbon.

Zienkiewicz, O. C. \& Cormeau, I. C. (1974). Viscoplasticity, plasticity and creep in elastic solids: a unified numerical solution approach. Int. J. Numer. Methods Engng 8, 821-845.

Zienkiewicz, O. C. \& Taylor, R. L. (2000). The finite element method. Vol 2: Solid mechanics. Oxford: Butterworth-Heinemann. 